\title{
Geopolitical Risks and Stock Market Dynamics of the BRICS*
}

\author{
Mehmet Balcilar^, Matteo Bonato ${ }^{\star}$, Riza Demirer^ and Rangan Gupta
}

\section{Highlights}

- BRICS stock markets do not react to geopolitical risks (GPRs) in a uniform way.

- GPRs generally drive stock market volatility rather than returns.

- The effect of GPRs is particularly strong at return quantiles below the mean.

- Russia is the market most affected by GPRs, while India is the most resilient.

\begin{abstract}
This paper examines the effect of geopolitical uncertainty on return and volatility dynamics in the BRICS stock markets via nonparametric causality-in-quantiles tests. The effect of geopolitical risks (GPRs) is found to be heterogeneous across the BRICS stock markets, suggesting that news regarding geopolitical tensions do not affect return dynamics in these markets in a uniform way. GPRs are generally found to impact stock market volatility measures rather than returns, and often at return quantiles below the median, indicating the role of GPRs as a driver of bad volatility in these markets. While Russia bears the greatest risk exposure to GPRs in terms of both return and volatility, India is found to be the most resilient BRICS nation in the group. Noting that geopolitical shocks and in particular terrorist incidents are largely unanticipated, our findings underscore the importance of a strong financial sector that can help return the market to stability and an open economy that allows local investors to diversify country-specific risks in their portfolios.
\end{abstract}

Keywords: Geopolitical Risks, Stock Returns, Volatility, BRICS.

\footnotetext{
* We would like to thank an anonymous referee for many helpful comments. However, any remaining errors are solely ours.

* Department of Economics, Eastern Mediterranean University, Famagusta, via Mersin 10, Northern Cyprus, Turkey and Department of Economics, University of Pretoria, Pretoria, 0002, South Africa; IPAG Business School, Paris, France. Email: mehmet@mbalcilar.net.

- Department of Economics and Econometrics, University of Johannesburg, Auckland Park, South Africa. Email: mbonato@,uj.ac.za.

- Corresponding author. Department of Economics and Finance, Southern Illinois University Edwardsville, Edwardsville, IL 62026- 1102, USA. Email: rdemire@siue.edu.

- Department of Economics, University of Pretoria, Pretoria, 0002, South Africa. Email: rangan.gupta@up.ac.za.
} 
JEL Codes: C22, G15.

\section{Introduction}

Geopolitical risks (GPRs) are believed to affect business cycles and financial markets, with GPRs being often cited by central bankers, financial press and business investors as one of the determinants of investment decisions (Caldara and Iacoviello, 2016). Against this backdrop, we use a novel nonparametric causality-in-quantiles test of Balcilar et al. (2016, forthcoming) to examine the impact of geopolitical tensions on the stock markets of Brazil, Russia, India, China, and South Africa (BRICS). For our purpose, we use both daily and monthly stock price data, and the recently developed news-based indices of GPR by Caldara and Iacoviello (2016).

The nonparametric causality-in-quantiles test combines elements of the test for nonlinear causality of $k$-th order developed by Nishiyama et al. (2011) with the causality-in-quantiles test developed by Jeong et al. (2012) and, hence, can be considered to be a generalization of the former. The causality-in-quantile approach has the following three novelties: Firstly, it is robust to misspecification errors as it detects the underlying dependence structure between the examined time series, which could prove to be particularly important as it is well known that

stock returns display nonlinear dynamics (see Bekiros et al., forthcoming, for a detailed discussion in this regard). Secondly, via this methodology, we are able to test not only for causality-in-mean ( $1^{\text {st }}$ moment), but also for causality that may exist in the tails of the joint distribution of the variables, which in turn, is important if the dependent variable has fat-tails something we show below to hold for stock returns. Finally, we are also able to investigate causality-in-variance and, thus, volatility spillovers. Such an investigation is important because, during some periods, causality in the conditional-mean may not exist while, at the same time, higher-order interdependencies may turn out to be significant. 
The decision to investigate the BRICS countries was quite natural. The BRICS have grown rapidly and have become more integrated with the developed world in terms of trade and investment. They account for more than a quarter of the world's land area, slightly less than a half of the world's population and about one sixth of the world's GDP (Mensi et al., 2014). Understandably, given the financial dependence in the modern globalized world, the current and potential growth of the BRICS countries has important implications for the capitalization of the international equity markets. The BRIC countries are expected to account for more than $40 \%$ of the global stock market capitalization by 2030, with China overtaking the United States in equity market capitalization (Mensi et al., 2014). Recently, several studies (see for example Mensi et al., 2014; 2016 and references cited therein), have added South Africa into the BRIC group. This is because of the fact that South Africa has also a fast-growing economy, with rapid financial market development and sophistication. In addition, South Africa is also one of the world's largest exporters of some strategic commodities that include coal, chrome, gold, and iron (Cakan and Gupta, 2016). Thus, the inclusion of South Africa into the BRICS group provides investment diversification opportunities and, hence, deserves to be considered simultaneously with the four other members of the BRICS.

Note that, to the best of our knowledge this is the first paper to analyze movements in the BRICS stock markets based on GPRs. In the process, our paper adds to the related literature of terror attacks on financial markets (Chen and Siems, 2004; Drakos, 2004, 2010; Eldor and Melnick, 2004; Hon et al., 2004; Isreal et al., 2004; Johnston and Nedelescu, 2005; Karolyi and Martell, 2005; Chuliá et al., 2007; Abadie and Gardeazabal, 2008; Arin et al., 2008; Barros and GilAlana, 2008; Fernandez, 2008; Nikkinen et al., 2008; Kollias et al., 2010, 2011a, b, 2013a; Chesney et al., 2011; Christofis et al., 2013; Balcilar et al., forthcoming, 2016a; Gupta et al., 2016). In sum researchers, find that not only domestic terror attacks, but also attacks on major financial markets, tend to affect both stock returns and volatility. However, GPR indices are much 
broader, as it includes not only terror attacks but also other forms of geopolitical tensions like war risks, military threats, Middle East tensions, and hence, captures a wider array of exogenous global uncertainty. ${ }^{1}$ In addition, unlike the literature, where terror attacks are modeled through dummy variables, which could capture the effect of any major multiple events; and are conditional mean-based analyses, ${ }^{2}$ we analyze the entire conditional distributions of stock returns and volatility, and hence, capture the effect on the various phases (bear, normal, bull) of the stock markets, due to geopolitical risks, measured by a continuous news-based index. One general difference with the terror attacks literature is that we rely primarily on monthly, rather than daily data (though we compute realized volatility based on daily data), since the GPR indices are monthly.

Our findings suggest that the effect of GPRs is heterogeneous across the BRICS stock markets, implying that news regarding geopolitical tensions do not affect return dynamics in these markets in a uniform way. In general, GPRs are found to have a more consistent effect on market volatility measures, rather than returns, implying the presence of possible volatility spillovers into these markets as a result of their exposures with respect to geopolitical tensions. Interestingly, the effect of GPRs on market volatility is found to be more consistent at quantiles below the conditional median of returns, suggesting that GPRs in fact contribute to bad volatility in these markets. Examining the findings across the BRICS nations, we find that Russia bears the greatest risk exposure to GPRs with significant causality observed from GPR indices to both market return and volatility in this market. On the other hand, India is found to be the most resilient BRICS nation to GPR shocks, with no significant causal relationships observed.

\footnotetext{
1 A related line of research has used either dummy variables or time-varying approaches to relate to periods of geopolitical tensions to analyze spillovers between oil and stock markets (see for example, Kollias et al., (2013b) and Antonakakis et al., (2014) and references cited therein).

${ }^{2}$ Few of exceptions are Balcilar et al., (forthcoming, 2016a) and Gupta et al., (2016) which uses quantile-based methods, but then again (as discussed above), they looked at terror attacks only, rather than GPR, on G7 stock markets, dollar-pound exchange rate and gold prices respectively.
} 
We argue that a combination of factors including exposure to political and financial risks, the strength of domestic demand and exposure to the U.S dollar in foreign exchange reserves drive the heterogeneity in the reaction of these emerging stock markets to geopolitical risks. Noting that geopolitical shocks and in particular terrorist incidents are largely unanticipated, our findings underscore the importance of a strong financial sector that can help return the market to stability and an open economy that allows local investors to diversify country specific risks in their portfolios. This issue is particularly important for emerging markets, like those in the BRICS, as these markets are often subject to the flow of 'hot money' in and out of the financial system that can be rather destabilizing given their exposure to geopolitical risks, as evidenced in this study.

The rest of the paper is organized as follows: Section 2 presents the methodology and lays out the measure of realized volatility, while Section 3 discusses the data and the results. Finally, Section 4 concludes.

\section{Methodology}

We present here a novel methodology, as proposed by Balcilar et al., (2016, forthcoming b), for the detection of nonlinear causality via a hybrid approach based on the frameworks of Nishiyama et al., (2011) and Jeong et al., (2012). We denote returns on stock as $y_{t}$ and the nine different GPR indexes as $x_{t}$, used in turn. Following Jeong et al., (2012), the quantile-based causality is defined as follows: ${ }^{3} x_{t}$ does not cause $y_{t}$ in the $\theta$-quantile with respect to the lagvector of $\left\{y_{t-1}, \ldots, y_{t-p}, x_{t-1}, \ldots, x_{t-p}\right\}$ if

$$
Q_{\theta}\left(y_{t} \mid y_{t-1}, \ldots, y_{t-p}, x_{t-1}, \ldots, x_{t-p}\right)=Q_{\theta}\left(y_{t} \mid y_{t-1}, \ldots, y_{t-p}\right)
$$

$x_{t}$ is a prima facie cause of $y_{t}$ in the $\theta$-th quantile with respect to $\left\{y_{t-1}, \ldots, y_{t-p}, x_{t-1}, \ldots, x_{t-p}\right\}$ if

$$
Q_{\theta}\left(y_{t} \mid y_{t-1}, \ldots, y_{t-p}, x_{t-1}, \ldots, x_{t-p}\right) \neq Q_{\theta}\left(y_{t} \mid y_{t-1}, \ldots, y_{t-p}\right)
$$

\footnotetext{
${ }^{3}$ The exposition in this section closely follows Nishiyama et al., (2011) and Jeong et al., (2012).
} 
where $Q_{\theta}\left(y_{t} \mid \cdot\right)$ is the $\theta$-th quantile of $y_{t}$ depending on $t$ and $0<\theta<1$.

Let $Y_{t-1} \equiv\left(y_{t-1}, \ldots, y_{t-p}\right), X_{t-1} \equiv\left(x_{t-1}, \ldots, x_{t-p}\right), Z_{t}=\left(X_{t}, Y_{t}\right)$, and $F_{y_{t} \mid Z_{t-1}}\left(y_{t} \mid Z_{t-1}\right)$ and $F_{y_{t} \mid Y_{t-1}}\left(y_{t} \mid Y_{t-1}\right)$ denote the conditional distribution functions of $y_{t}$ given $Z_{t-1}$ and $Y_{t-1}$, respectively. The conditional distribution $F_{y_{t} \mid Z_{t-1}}\left(y_{t} \mid Z_{t-1}\right)$ is assumed to be absolutely continuous in $y_{t}$ for almost all $Z_{t-1}$. If we denote $Q_{\theta}\left(Z_{t-1}\right) \equiv Q_{\theta}\left(y_{t} \mid Z_{t-1}\right)$ and $Q_{\theta}\left(Y_{t-1}\right) \equiv$ $Q_{\theta}\left(y_{t} \mid Y_{t-1}\right)$, we have $F_{y_{t} \mid Z_{t-1}}\left\{Q_{\theta}\left(Z_{t-1}\right) \mid Z_{t-1}\right\}=\theta$ with probability one. Consequently, the hypotheses to be tested based on definitions (1) and (2) are:

$$
\begin{aligned}
& H_{0}: P\left\{F_{y_{t} \mid Z_{t-1}}\left\{Q_{\theta}\left(Y_{t-1}\right) \mid Z_{t-1}\right\}=\theta\right\}=1 \\
& H_{1}: P\left\{F_{y_{t} \mid Z_{t-1}}\left\{Q_{\theta}\left(Y_{t-1}\right) \mid Z_{t-1}\right\}=\theta\right\}<1
\end{aligned}
$$

Jeong et al., (2012) employs the distance measure $J=\left\{\varepsilon_{t} E\left(\varepsilon_{t} \mid Z_{t-1}\right) f_{Z}\left(Z_{t-1}\right)\right\}$ where $\varepsilon_{t}$ is the regression error term and $f_{Z}\left(Z_{t-1}\right)$ is the marginal density function of $Z_{t-1}$. The regression error $\varepsilon_{t}$ emerges based on the null in (3), which can only be true if and only if $E\left[\mathbf{1}\left\{y_{t} \leq Q_{\theta}\left(Y_{t-1}\right) \mid Z_{t-1}\right\}\right]=\theta$ or equivalently $\mathbf{1}\left\{y_{t} \leq Q_{\theta}\left(Y_{t-1}\right)\right\}=\theta+\varepsilon_{t}$, where $\mathbf{1}\{\cdot\}$ is an indicator function. Jeong et al. (2012) specify the distance measure as follows:

$$
J=E\left[\left\{F_{y_{t} \mid Z_{t-1}}\left\{Q_{\theta}\left(Y_{t-1}\right) \mid Z_{t-1}\right\}-\theta\right\}^{2} f_{Z}\left(Z_{t-1}\right)\right]
$$

In Eq. (3), it is important to note that $J \geq 0$, i.e., the equality holds if and only if $H_{0}$ in (5) is true, while $J>0$ holds under the alternative $H_{1}$ in Eq. (4). Jeong et al., (2012) show that the feasible kernel-based sample analog of $J$ has the following form:

$$
\hat{J}_{T}=\frac{1}{T(T-1) h^{2 p}} \sum_{t=p+1}^{T} \sum_{s=p+1, s \neq t}^{T} K\left(\frac{Z_{t-1}-Z_{s-1}}{h}\right) \hat{\varepsilon}_{t} \hat{\varepsilon}_{S}
$$

where $K(\cdot)$ is the kernel function with bandwidth $h, T$ is the sample size, $p$ is the lag-order, and $\hat{\varepsilon}_{t}$ is the estimate of the unknown regression error, which is estimated as follows:

$$
\hat{\varepsilon}_{t}=\mathbf{1}\left\{y_{t} \leq \hat{Q}_{\theta}\left(Y_{t-1}\right)\right\}-\theta
$$


$\hat{Q}_{\theta}\left(Y_{t-1}\right)$ is an estimate of the $\theta$-th conditional quantile of $y_{t}$ given $Y_{t-1}$. Below, we estimate $\hat{Q}_{\theta}\left(Y_{t-1}\right)$ using the nonparametric kernel method as:

$$
\hat{Q}_{\theta}\left(Y_{t-1}\right)=\hat{F}_{y_{t} \mid Y_{t-1}}^{1}\left(\theta \mid Y_{t-1}\right)
$$

where $\hat{F}_{y_{t} \mid Y_{t-1}}\left(y_{t} \mid Y_{t-1}\right)$ is the Nadarya-Watson kernel estimator given by:

$$
\widehat{F}_{y_{t} \mid Y_{t-1}}\left(y_{t} \mid Y_{t-1}\right)=\frac{\sum_{s=p+1, s \neq t}^{T} L\left(\frac{Y_{t-1}-Y_{S-1}}{h}\right) \mathbf{1}\left(y_{s} \leq y_{t}\right)}{\sum_{s=p+1, s \neq t}^{T} L\left(\frac{Y_{t-1}-Y_{s-1}}{h}\right)}
$$

with $L(\cdot)$ denoting the kernel function and $h$ the bandwidth.

In an extension of the Jeong et al., (2012) framework, we develop a test for the 2nd moment. In particular, we want to test the volatility causality running from the various GPR indices to volatility of stock market returns. Causality in the $k$-th moment generally implies causality in the $m$-th moment for $k<m$. Firstly, we employ the nonparametric Granger quantile causality approach by Nishiyama et al., (2011). In order to illustrate the causality in higher order moments, consider the following process for $y_{t}$ :

$$
y_{t}=g\left(Y_{t-1}\right)+\sigma\left(X_{t-1}\right) \varepsilon_{t}
$$

where $\varepsilon_{t}$ is a white noise process; and $g(\cdot)$ and $\sigma(\cdot)$ are unknown functions that satisfy certain conditions for stationarity. However, this specification does not allow for Granger-type causality testing from $X_{t-1}$ to $y_{t}$, but could possibly detect the "predictive power" from $X_{t-1}$ to $y_{t}^{2}$ when $\sigma(\cdot)$ is a general nonlinear function. Hence, the Granger causality-in-variance definition does not require an explicit specification of squares for $X_{t-1}$. We re-formulate Eq. (10) into a null and alternative hypothesis for causality in variance as follows:

$$
\begin{aligned}
& H_{0}: P\left\{F_{y_{t}^{2} \mid Z_{t-1}}\left\{Q_{\theta}\left(Y_{t-1}\right) \mid Z_{t-1}\right\}=\theta\right\}=1 \\
& H_{1}: P\left\{F_{y_{t}^{2} \mid Z_{t-1}}\left\{Q_{\theta}\left(Y_{t-1}\right) \mid Z_{t-1}\right\}=\theta\right\}<1
\end{aligned}
$$

To obtain a feasible test statistic for testing the null in Eq. (10), we replace $y_{t}$ in Eq. (6) - (9) with $y_{t}^{2}$. Incorporating the Jeong et al., (2012) approach we overcome the problem that causality in 
the conditional 1 st moment (mean) imply causality in the 2 nd moment (variance). In order to overcome this problem, we interpret the causality in higher order moments using the following model:

$$
y_{t}=g\left(X_{t-1}, Y_{t-1}\right)+\varepsilon_{t}
$$

Thus, higher order quantile causality can be specified as:

$$
\begin{aligned}
& H_{0}: P\left\{F_{y_{t}^{k} \mid Z_{t-1}}\left\{Q_{\theta}\left(Y_{t-1}\right) \mid Z_{t-1}\right\}=\theta\right\}=1 \quad \text { for } k=1,2, \ldots, K \\
& H_{1}: P\left\{F_{y_{t}^{k} \mid Z_{t-1}}\left\{Q_{\theta}\left(Y_{t-1}\right) \mid Z_{t-1}\right\}=\theta\right\}<1 \quad \text { for } k=1,2, \ldots, K
\end{aligned}
$$

Integrating the entire framework, we define that $x_{t}$ Granger causes $y_{t}$ in quantile $\theta$ up to $K$-th moment utilizing Eq. (14) to construct the test statistic of Eq. (6) for each $k$. However, it can be shown that it is not easy to combine the different statistics for each $k=1,2, \ldots, K$ into one statistic for the joint null in Eq. (14) because the statistics are mutually correlated (Nishiyama et al., 2011). To efficiently address this issue, we include a sequential-testing method as described by Nishiyama $e t$ al. (2011) with some modifications. Firstly, we test for the nonparametric Granger causality in the 1 st moment $(k=1)$. Rejecting the null of non-causality means that we can stop and interpret this result as a strong indication of possible Granger quantile causality-in-variance. Nevertheless, failure to reject the null for $k=1$, does not automatically leads to no-causality in the 2nd moment, thus we can still construct the tests for $k=2$. Finally, we can test the existence of causality-in-variance, or the causality-in-mean and variance successively. The empirical implementation of causality testing via quantiles entails specifying three important choices: the bandwidth $h$, the lag order $p$, and the kernel type for $K(\cdot)$ and $L(\cdot)$ in Eq. (6) and (9), respectively. In our study, a lag order of 1 is used based on the Schwarz Information Criterion (SIC) under a VAR comprising of stock returns and a specific GPR index. The SIC being parsimonious when it comes to choosing lags compared to other alternative lag-length selection criterion, helps us to prevent issues of overparametrization commonly associated with 
nonparametric approaches. In addition, the choice of one lag is also in line with the predictive regression framework used traditionally in predicting stock returns (Rapach and Zhou, 2013). The bandwidth value is selected using the least squares cross-validation method. Lastly, for $K(\cdot)$ and $L(\cdot)$ we employ Gaussian-type kernels.

An advantage of having high frequency (daily) data for stock indices is that we are also able to compute a measure of realized volatility, which allows us to check the robustness of our findings, especially related to the measure of market volatility. The measure that we consider is the classical estimator of realized volatility, i.e. the sum of squared daily returns (Andersen and Bollerslev, 1998), expressed as

$$
R V_{t}=\sum_{i=1}^{M} r_{t, i}^{2}
$$

where $r_{t, i}$ is the daily $M \times 1$ return vector and $i=1, \ldots, M$ the number of daily returns.

\section{Data and Empirical Findings}

\subsection{Data}

The monthly data on geopolitical risk is obtained from the recent work of Caldara and Iacoviello (2016). This paper constructs various GPR indices by counting the occurrence of words related to geopolitical tensions, derived from automated text-searches in leading 11 national and international newspapers. The authors look into the following newspapers: The Boston Globe, Chicago Tribune, The Daily Telegraph, Financial Times, The Globe and Mail, The Guardian, Los Angeles Times, The New York Times, The Times, The Wall Street Journal, and The Washington Post. The index is constructed searching the electronic archives of each newspaper from January 1985 to April 2016 for eight phrases, namely: "geopolitical risk(s)", "geopolitical concern(s)", "geopolitical tension(s)", "geopolitical uncertainty(ies)", "war risk(s)" (or "risk(s) of war"), and "military threat(s)", "terrorist threat(s)", "terrorist act(s)", and "Middle East AND tensions". Based on these search criteria, Caladara and Iacoviello (2016) calculate the index by 
counting in each of the above-mentioned 11 newspapers, for each month, how many articles contain the search terms above. The index is then normalized to average a value of 100 in the 2000-2009 decade. There are nine-variants of GPR indices developed, all of which we use in our study to determine the importance of the types of geopolitical tensions that affect the BRICS stock markets. The data on the GPR indices are available for download from: https://www2.bc.edu/matteo-iacoviello/gpr.htm. The indices considered are: Benchmark GPR with Threats and Acts and Middle East (GPRME); GPR Index (GPR0); GPR Index less War and Military (GPRNOWAR); GPR Index with Terrorist Threats (GPRTERROR0); GPR with Threats and Acts (GPRTERROR1); GPR with Threats and Attacks (GPRTERROR2); GPR with Threats and War Ultimatums (GPRTERROR3); GPR with Threats Acts and Arms Control (GPRTERROR1ARMS); and, GPRTERROR1 with 7 papers (GPRTERROR1N7) instead of the 11 used for the other indices.

Both daily and monthly data on stock price indices for the BRICS countries are obtained from Datstream of Thomson Reuters. Stock-market returns are measured in terms of the firstdifference of the natural log of the stock-market index of each of the BRICS countries. Using stock-market returns ensures that the dependent variable is stationary, just like the various GPR indices - a requirement for our causality analysis. ${ }^{4}$ Based on data availability, the starting periods for each of the countries vary, however the end date is always April, 2016 to correspond with the end point of the GPR indices. Brazil starts in September, 1994 (260 observations); Russia in March, 1998 (218 observations); India in February, 1990 (315 observations); China in September, 1993 (272 observations); and South Africa in January, 1985 (376 observations). ${ }^{5}$ Note that we standardize the various GPR indices to have a variance of unity over the respective sub-sample of the five countries, so that we can compare the strength of the effect of the GPR indices on stock returns and volatility.

\footnotetext{
${ }^{4}$ Details of the unit-root tests are available upon request from the authors.

${ }^{5}$ Realized volatility estimates are based on 5663, 4732, 6838, 5908, and 11273 daily observations for Brazil, Russia, India, China and South Africa respectively.
} 
Table 1 presents the summary statistics for the monthly stock returns. All markets have experienced positive mean returns despite the inclusion of the 2007/2008 global financial crisis period in the sample. While India and Russia lead the pack with higher mean returns experienced during the sample period, Russia stands out with the highest level of market volatility. We observe that stock index returns in these markets, with the exception of China, are non-normal with heavy tails, providing further justification for the quantile focus in our causality tests.

Table 1. Summary Statistics

\begin{tabular}{|l|r|r|r|r|r|}
\hline Statistic & BRAZIL & RUSSIA & INDIA & CHINA & SOUTH AFRICA \\
\hline Mean & 0.8070 & 1.6206 & 1.0699 & 0.5338 & 0.6094 \\
\hline Median & 0.9716 & 2.1940 & 1.1677 & 0.5990 & 0.8465 \\
\hline Maximum & 23.0507 & 61.9642 & 49.1998 & 35.5310 & 27.9091 \\
\hline Minimum & -36.3915 & -43.8887 & -34.6722 & -26.3058 & -40.4432 \\
\hline Std. Dev. & 7.3553 & 11.7181 & 9.4531 & 10.0411 & 8.1353 \\
\hline Skewness & -0.6556 & 0.2772 & 0.1881 & 0.0909 & -0.6409 \\
\hline Kurtosis & 5.6577 & 7.6569 & 5.9823 & 3.5727 & 5.8209 \\
\hline Jarque-Bera & 95.1492 & 199.7806 & 118.5910 & 4.0917 & 150.4101 \\
\hline Probability & 0.0000 & 0.0000 & 0.0000 & 0.1293 & 0.0000 \\
\hline Observations & 260 & 218 & 315 & 272 & 376 \\
\hline
\end{tabular}

Note: Std. Dev. stands for standard deviation, while probability corresponds to the Jarque-Bera test of normality.

\subsection{Empirical Findings}

Tables 2-6 provide the results of the causality-in-quantiles tests for Brazil, Russia, India, China and South Africa, respectively. Panels A, B and C in the tables present the results for market return, volatility (measured by squared returns), and realized volatility described in Equation 16, respectively. In each table, test statistics for alternative quantiles of the conditional distribution of returns are provided with the cells marked with asterisk indicating the rejection of the null hypothesis of non-causality (Equation 14) at 5\% significance level.

Examining the findings across the five markets, we observe that the effect of GPRs is heterogeneous across the BRICS stock markets, suggesting that news regarding geopolitical tensions do not affect return dynamics in these markets in a uniform way. In general, GPRs are 
Table 2. Causality-in-Quantiles Test for Brazil

\begin{tabular}{|c|c|c|c|c|c|c|c|c|c|}
\hline & \multicolumn{9}{|c|}{ Panel A: Returns } \\
\hline Quantile & GPRME & GPR0 & GPRNOWAR & GPRTERROR0 & GPRTERROR1 & GPRTERROR2 & GPRTERROR3 & GPTERROR1ARMS & GPRTERROR1N7 \\
\hline 0.1 & 0.0402 & 0.0200 & 0.0729 & 0.0377 & 0.0289 & 0.0183 & 0.0339 & 0.0127 & 0.0387 \\
\hline 0.15 & 0.0323 & 0.0432 & 0.0599 & 0.0361 & 0.0246 & 0.0224 & 0.0311 & 0.0367 & 0.0375 \\
\hline 0.2 & 0.0808 & 0.0769 & 0.1134 & 0.1057 & 0.0641 & 0.0580 & 0.0995 & 0.0633 & 0.0821 \\
\hline 0.25 & 0.0974 & 0.0480 & 0.0666 & 0.1507 & 0.0732 & 0.0323 & 0.1339 & 0.0523 & 0.1275 \\
\hline 0.3 & 0.0902 & 0.0569 & 0.0697 & 0.1229 & 0.0744 & 0.0540 & 0.1115 & 0.0623 & 0.1047 \\
\hline 0.35 & 0.0553 & 0.0354 & 0.0528 & 0.0797 & 0.0371 & 0.0242 & 0.0764 & 0.0346 & 0.0574 \\
\hline 0.4 & 0.0912 & 0.0727 & 0.0730 & 0.1132 & 0.0616 & 0.0451 & 0.1004 & 0.0658 & 0.0613 \\
\hline 0.45 & 0.0863 & 0.0809 & 0.0775 & 0.1125 & 0.0678 & 0.0499 & 0.0948 & 0.0937 & 0.0533 \\
\hline 0.5 & 0.0774 & 0.0680 & 0.0599 & 0.0657 & 0.0488 & 0.0385 & 0.0657 & 0.0559 & 0.0587 \\
\hline 0.55 & 0.0774 & 0.0895 & 0.0912 & 0.0942 & 0.0629 & 0.0645 & 0.0831 & 0.0687 & 0.0612 \\
\hline 0.6 & 0.0814 & 0.0450 & 0.0461 & 0.0640 & 0.0468 & 0.0381 & 0.0549 & 0.0420 & 0.0674 \\
\hline 0.65 & 0.1431 & 0.0778 & 0.0839 & 0.0932 & 0.0718 & 0.0520 & 0.0771 & 0.0384 & 0.0983 \\
\hline 0.7 & 0.1232 & 0.1002 & 0.1117 & 0.0718 & 0.0698 & 0.0916 & 0.0734 & 0.0677 & 0.0931 \\
\hline 0.75 & 0.0896 & 0.1000 & 0.0988 & 0.0659 & 0.0704 & 0.0955 & 0.0689 & 0.0656 & 0.0913 \\
\hline 0.8 & 0.1055 & 0.1246 & 0.1242 & 0.0776 & 0.0783 & 0.0860 & 0.0797 & 0.0771 & 0.1012 \\
\hline 0.85 & 0.0897 & 0.0988 & 0.1124 & 0.0502 & 0.0508 & 0.0553 & 0.0369 & 0.0416 & 0.0736 \\
\hline \multirow[t]{2}{*}{0.9} & 0.0614 & 0.0814 & 0.0947 & 0.0448 & 0.0346 & 0.0252 & 0.0384 & 0.0321 & 0.0382 \\
\hline & \multicolumn{9}{|c|}{ Panel B: Volatility (Squared Returns) } \\
\hline Quantile & GPRME & GPR0 & GPRNOWAR & GPRTERROR0 & GPRTERROR1 & GPRTERROR2 & GPRTERROR3 & GPTERROR1ARMS & GPRTERROR1N7 \\
\hline 0.1 & 0.7896 & 0.6393 & 0.7948 & 1.0820 & 0.9139 & 0.9100 & 1.0384 & 1.1258 & 0.9929 \\
\hline 0.15 & 1.0969 & 0.7823 & 1.1144 & 1.6575 & 1.3230 & 0.7136 & 1.7420 & 1.3932 & 1.3744 \\
\hline 0.2 & 1.4525 & 0.8488 & 1.8372 & 1.5215 & 1.2593 & 0.8244 & 1.3975 & 1.3695 & 1.5148 \\
\hline 0.25 & 1.5400 & 1.0265 & $2.2319^{*}$ & 1.5283 & 1.3220 & 0.8264 & 1.4431 & 1.5014 & 1.5129 \\
\hline 0.3 & 1.7029 & 1.2361 & $1.9628^{*}$ & $2.0831^{*}$ & 1.7352 & 1.0456 & 1.8657 & 1.8414 & $2.0378^{*}$ \\
\hline 0.35 & 1.9550 & 1.0587 & 1.8704 & 1.8233 & 1.6222 & 0.9510 & 1.4951 & $2.1097^{*}$ & $2.1897^{*}$ \\
\hline
\end{tabular}




\begin{tabular}{|c|c|c|c|c|c|c|c|c|c|}
\hline 0.4 & $2.1585^{*}$ & 1.3006 & $2.6397^{*}$ & $2.0560^{*}$ & 1.9002 & 1.2552 & $1.9622^{*}$ & $2.3173^{*}$ & $2.7276^{*}$ \\
\hline 0.45 & $2.1923^{*}$ & 1.5267 & $2.5012^{*}$ & $2.0115^{*}$ & 2.0601 & 1.4208 & 1.8328 & $2.0143^{*}$ & $2.5089^{*}$ \\
\hline 0.5 & $2.5780^{*}$ & 1.8139 & $2.9270^{*}$ & $2.2371^{*}$ & 2.3447 & 1.5826 & $1.9628^{*}$ & $2.3162^{*}$ & $2.6181^{*}$ \\
\hline 0.55 & $2.3297^{*}$ & 1.8794 & $3.2146^{*}$ & $2.0609^{*}$ & 2.1301 & 1.4469 & 1.7262 & $2.2756^{*}$ & $2.5391^{*}$ \\
\hline 0.6 & $2.9996^{*}$ & 1.6247 & $2.5379^{*}$ & $2.0742^{*}$ & 2.4749 & 1.3332 & 1.8050 & $2.0623^{*}$ & $2.7270^{*}$ \\
\hline 0.65 & $2.7538^{*}$ & 1.0331 & $2.2944^{*}$ & 1.8395 & 2.0579 & 1.0572 & 1.7139 & 1.7191 & $2.7770^{*}$ \\
\hline 0.7 & $2.0715^{*}$ & 1.1674 & $2.0446^{*}$ & 1.7605 & 1.7012 & 1.0423 & 1.4836 & 1.6700 & $2.3803^{*}$ \\
\hline 0.75 & $2.2198^{*}$ & 1.3345 & $2.2067^{*}$ & 1.5645 & 1.5580 & 1.2074 & 1.2567 & 1.5045 & $1.9683^{*}$ \\
\hline 0.8 & 1.8563 & 1.6013 & $2.1443^{*}$ & 1.6463 & 1.5501 & 1.4220 & 1.4115 & 1.5663 & 1.3901 \\
\hline 0.85 & 1.3530 & 1.2136 & 1.1116 & 1.1130 & 0.7988 & 0.9635 & 0.8563 & 1.0743 & 0.9409 \\
\hline 0.9 & 1.0084 & 0.8353 & 1.2172 & 1.0140 & 0.6046 & 0.9959 & 0.7638 & 0.9786 & 0.7690 \\
\hline & \multicolumn{9}{|c|}{ Panel C: Realized Volatility } \\
\hline Quantile & GPRME & GPR0 & GPRNOWAR & GPRTERROR0 & GPRTERROR1 & GPRTERROR2 & GPRTERROR3 & GPTERROR1ARMS & GPRTERROR1N7 \\
\hline 0.1 & 0.9554 & 1.0548 & 0.5195 & 1.1012 & 0.6354 & 0.3796 & 0.8439 & 0.8114 & 0.6062 \\
\hline 0.15 & 1.5596 & 1.1053 & 0.7858 & 1.4679 & 1.2333 & 0.6512 & 1.1160 & 0.9891 & 0.8886 \\
\hline 0.2 & 1.6996 & 1.4043 & 0.7831 & 1.2188 & 1.2301 & 0.7267 & 1.2536 & 1.2634 & 1.0275 \\
\hline 0.25 & 1.5033 & 1.4134 & 0.7003 & 1.0289 & 1.1736 & 0.7126 & 1.0966 & 1.3201 & 1.1657 \\
\hline 0.3 & 1.6969 & 1.7410 & 0.7938 & 1.3232 & 1.3873 & 0.7883 & 1.2376 & 1.4387 & 1.4119 \\
\hline 0.35 & $2.2030^{*}$ & $2.0457^{*}$ & 0.8359 & 1.5297 & 1.6456 & 1.1384 & 1.3019 & 1.7997 & 1.4159 \\
\hline 0.4 & $2.8280^{*}$ & $2.0840^{*}$ & 1.4116 & 1.7088 & 1.8973 & 1.5187 & 1.4996 & $2.0364^{*}$ & $2.0792^{*}$ \\
\hline 0.45 & $2.4635^{*}$ & $2.0784^{*}$ & 1.3523 & 1.4160 & 1.4862 & 1.5647 & 1.4867 & 1.9517 & 1.7578 \\
\hline 0.5 & 1.9370 & 1.7390 & 1.4176 & 1.3398 & 1.3036 & 1.5094 & 1.2852 & 1.6332 & 1.5848 \\
\hline 0.55 & 1.6983 & 1.8156 & 1.4865 & 1.4440 & 1.3936 & 1.5341 & 1.2786 & 1.7431 & 1.7008 \\
\hline 0.6 & 1.4759 & 1.6064 & 0.9580 & 1.3540 & 1.0910 & 1.1430 & 1.1196 & 1.5187 & 1.3614 \\
\hline 0.65 & 1.5050 & $1.9890^{*}$ & 0.9800 & 1.5286 & 1.2644 & 1.2989 & 1.2548 & 1.5347 & 1.6791 \\
\hline 0.7 & 1.5192 & 1.9156 & 1.0751 & 1.7231 & 1.3787 & 1.2610 & 1.4490 & 1.4549 & 1.4791 \\
\hline 0.75 & 1.3883 & 1.6420 & 0.8973 & 1.6793 & 1.2820 & 0.9265 & 1.5672 & 1.6443 & 1.3716 \\
\hline 0.8 & 1.0525 & 1.2284 & 0.8747 & 1.4040 & 0.9302 & 0.6265 & 1.1309 & 1.1433 & 1.2870 \\
\hline
\end{tabular}




\begin{tabular}{|r|r|r|r|r|r|r|r|r|r|} 
& 1.1926 & 1.4015 & 1.2128 & 1.2016 & 0.8896 & 0.6745 & 1.0939 & 1.1984 & 1.2751 \\
\hline 0.9 & 0.8520 & 0.8963 & 1.0384 & 0.8986 & 0.8495 & 0.5097 & 0.9848 & 1.0060 & 0.8971 \\
\hline
\end{tabular}

Note: Benchmark GPR with Threats and Acts and Middle East (GPRME); GPR Index (GPR0); GPR Index less War and Military (GPRNOWAR); GPR Index with Terrorist Threats (GPRTERROR0); GPR with Threats and Acts (GPRTERROR1); GPR with Threats and Attacks (GPRTERROR2); GPR with Threats and War Ultimatums (GPRTERROR3); GPR with Threats Acts and Arms Control (GPRTERROR1ARMS); and, GPRTERROR1 with 7 papers (GPRTERROR1N7). Entry in a cell marked with a “*”indicates the rejection of the null of non-causality at $5 \%$ level of significance (i.e., 1.96). 
Table 3. Causality-in-Quantiles Test for Russia

\begin{tabular}{|c|c|c|c|c|c|c|c|c|c|}
\hline & \multicolumn{9}{|c|}{ Panel A: Returns } \\
\hline Quantile & GPRME & GPR0 & GPRNOWAR & GPRTERROR0 & GPRTERROR1 & GPRTERROR2 & GPRTERROR3 & GPTERROR1ARMS & GPRTERROR1N7 \\
\hline 0.1 & 1.5197 & 1.4637 & 1.6569 & 1.5032 & 1.7048 & 1.4382 & 1.4360 & $2.0148^{*}$ & 1.9456 \\
\hline 0.15 & 1.8966 & $1.9829^{*}$ & $2.2128^{*}$ & $2.3227^{*}$ & $2.4799^{*}$ & 1.8340 & $2.2006^{*}$ & $2.7098^{*}$ & $2.4332^{*}$ \\
\hline 0.2 & 1.8974 & 1.6465 & 1.8554 & $2.2675^{*}$ & $2.2266^{*}$ & 1.3312 & $2.1510^{*}$ & $2.6228^{*}$ & $2.1036^{*}$ \\
\hline 0.25 & 1.7748 & 1.6201 & 1.6586 & $2.1182^{*}$ & $2.1922^{*}$ & 1.1184 & $2.0614^{*}$ & $2.8593^{*}$ & $2.1754^{*}$ \\
\hline 0.3 & 1.9414 & $1.9876^{*}$ & 1.6156 & $2.4317^{*}$ & $2.1426^{*}$ & 1.2608 & $2.0287^{*}$ & $2.7797^{*}$ & $2.0819^{*}$ \\
\hline 0.35 & $1.9754^{*}$ & $2.1138^{*}$ & 1.5019 & $2.6302^{*}$ & $2.2395^{*}$ & 1.3301 & $2.0584^{*}$ & $2.7965^{*}$ & $2.2567^{*}$ \\
\hline 0.4 & 1.9069 & $2.3834^{*}$ & $2.0157^{*}$ & $2.6534^{*}$ & $2.1694^{*}$ & 1.2403 & $1.9987^{*}$ & $2.6453^{*}$ & $2.3516^{*}$ \\
\hline 0.45 & 1.8099 & 1.8771 & 1.8879 & $2.2911^{*}$ & $2.1145^{*}$ & 1.3955 & 1.9331 & $2.5983^{*}$ & $2.4516^{*}$ \\
\hline 0.5 & $2.1734^{*}$ & 1.9185 & $1.9608^{*}$ & $2.5833^{*}$ & $2.3389^{*}$ & 1.7304 & $2.2914^{*}$ & $2.6906^{*}$ & $2.7482^{*}$ \\
\hline 0.55 & 1.8313 & 1.6156 & $1.9773^{*}$ & $2.3289^{*}$ & $2.2592^{*}$ & 1.4307 & $2.1391^{*}$ & $2.9411^{*}$ & $2.3458^{*}$ \\
\hline 0.6 & $2.1636^{*}$ & 1.7169 & $2.2588^{*}$ & $2.6778^{*}$ & $2.2754^{*}$ & $2.0596^{*}$ & $2.2717^{*}$ & $3.0198^{*}$ & $2.2751^{*}$ \\
\hline 0.65 & $2.6108^{*}$ & 1.8850 & $2.0533^{*}$ & $3.2519^{*}$ & $2.7167^{*}$ & $2.6583^{*}$ & $2.7933^{*}$ & $2.6040^{*}$ & $2.3770^{*}$ \\
\hline 0.7 & $2.6120^{*}$ & $2.1898^{*}$ & $2.1813^{*}$ & $2.6337^{*}$ & $2.4974^{*}$ & $2.3408^{*}$ & $2.3413^{*}$ & $2.3071^{*}$ & $2.5554^{*}$ \\
\hline 0.75 & $2.5852^{*}$ & $1.9877^{*}$ & $2.3441^{*}$ & $2.3349^{*}$ & $2.3349^{*}$ & $2.3064^{*}$ & $2.0477^{*}$ & $2.0882^{*}$ & $2.4399^{*}$ \\
\hline 0.8 & $2.9766^{*}$ & 1.8595 & $2.3416^{*}$ & $2.5371^{*}$ & $2.4416^{*}$ & $2.1785^{*}$ & $2.1553^{*}$ & $2.0921^{*}$ & $2.6025^{*}$ \\
\hline 0.85 & $2.5023^{*}$ & 1.5875 & 1.9094 & $2.3390^{*}$ & $1.9604^{*}$ & 1.6376 & 1.7779 & 1.5909 & $2.1178^{*}$ \\
\hline \multirow[t]{2}{*}{0.9} & 1.7631 & 1.1331 & 1.5706 & 1.5982 & 1.5484 & 1.3655 & 1.3461 & 1.2287 & 1.6188 \\
\hline & \multicolumn{9}{|c|}{ Panel B: Volatility (Squared Returns) } \\
\hline Quantile & GPRME & GPR0 & GPRNOWAR & GPRTERROR0 & GPRTERROR1 & GPRTERROR2 & GPRTERROR3 & GPTERROR1ARMS & GPRTERROR1N7 \\
\hline 0.1 & 1.8850 & 1.6307 & 1.4426 & 1.4791 & 1.5866 & 1.1047 & 1.6179 & 1.6185 & 1.7336 \\
\hline 0.15 & $2.9954^{*}$ & 1.9344 & 1.8142 & $2.4701^{*}$ & $2.3498^{*}$ & 1.5050 & $2.5804^{*}$ & $2.6449^{*}$ & $2.3677^{*}$ \\
\hline 0.2 & $3.1070^{*}$ & $2.1410^{*}$ & $1.9702^{*}$ & $2.7515^{*}$ & $2.7070^{*}$ & $1.9965^{*}$ & $2.8309^{*}$ & $2.8190^{*}$ & $2.5830^{*}$ \\
\hline 0.25 & $2.9588^{*}$ & $2.2291^{*}$ & $2.4242^{*}$ & $2.9637^{*}$ & $2.8748^{*}$ & 1.8484 & $2.9692^{*}$ & $2.8500^{*}$ & $2.3723^{*}$ \\
\hline 0.3 & $2.8872^{*}$ & $2.5222^{*}$ & $2.7419^{*}$ & $2.9214^{*}$ & $2.7894^{*}$ & 1.8216 & $3.2878^{*}$ & $3.4025^{*}$ & $2.5932^{*}$ \\
\hline
\end{tabular}




\begin{tabular}{|c|c|c|c|c|c|c|c|c|c|}
\hline 0.35 & $2.9641^{*}$ & $2.4977^{*}$ & $2.9599^{*}$ & $2.6543^{*}$ & $2.9292^{*}$ & 1.6544 & $3.1355^{*}$ & $3.2980^{*}$ & $2.7097^{*}$ \\
\hline 0.4 & $3.5593^{*}$ & $2.8807^{*}$ & $3.1731^{*}$ & $2.8429^{*}$ & $2.9739^{*}$ & $2.0146^{*}$ & $3.2052^{*}$ & $3.4503^{*}$ & $3.2773^{*}$ \\
\hline 0.45 & $3.7544^{*}$ & $2.8066^{*}$ & $3.1226^{*}$ & $2.8307^{*}$ & $2.9709^{*}$ & 1.8940 & $3.2958^{*}$ & $3.5568^{*}$ & $3.3167^{*}$ \\
\hline 0.5 & $3.1190^{*}$ & $2.6392^{*}$ & $3.3811^{*}$ & $2.7604^{*}$ & $3.0891^{*}$ & $1.9802^{*}$ & $3.1192^{*}$ & $2.7718^{*}$ & $3.0732^{*}$ \\
\hline 0.55 & $3.3705^{*}$ & $2.6395^{*}$ & $2.8106^{*}$ & $2.4851^{*}$ & $2.8571^{*}$ & $2.2476^{*}$ & $2.8179^{*}$ & $2.6675^{*}$ & $3.0687^{*}$ \\
\hline 0.6 & $3.3766^{*}$ & $2.3030^{*}$ & $3.2440^{*}$ & $2.5211^{*}$ & $2.8687^{*}$ & $2.2703^{*}$ & $2.8080^{*}$ & $2.5189^{*}$ & $3.2985^{*}$ \\
\hline 0.65 & $3.4233^{*}$ & $2.3459^{*}$ & $3.5429^{*}$ & $2.4510^{*}$ & $2.5114^{*}$ & $2.1581^{*}$ & $2.5434^{*}$ & $2.5016^{*}$ & $3.3895^{*}$ \\
\hline 0.7 & $2.8475^{*}$ & $2.2234^{*}$ & $3.4903^{*}$ & $2.4625^{*}$ & $2.4969^{*}$ & $2.4434^{*}$ & $2.5112^{*}$ & $2.5701^{*}$ & $3.1292^{*}$ \\
\hline 0.75 & $2.7374^{*}$ & 2.2910* & $2.9411^{*}$ & $2.3706^{*}$ & $2.0761^{*}$ & $2.0944^{*}$ & $2.3818^{*}$ & $2.4673^{*}$ & $2.5194^{*}$ \\
\hline 0.8 & $2.2387^{*}$ & $2.4526^{*}$ & $2.2000^{*}$ & $2.3571^{*}$ & $2.1108^{*}$ & $2.0113 \mathrm{v}$ & $1.9898^{*}$ & $2.2495^{*}$ & $2.3275^{*}$ \\
\hline 0.85 & 1.7606 & 1.6466 & $2.0330^{*}$ & $2.2230^{*}$ & 1.7822 & 1.7039 & 1.4742 & 1.8164 & $2.1237^{*}$ \\
\hline 0.9 & 1.4642 & 1.8660 & $2.2438^{*}$ & 1.7165 & 1.7074 & 1.2738 & 1.3082 & 1.5226 & 1.8093 \\
\hline & \multicolumn{9}{|c|}{ Panel C: Realized Volatility } \\
\hline Quantile & GPRME & GPR0 & GPRNOWAR & GPRTERROR0 & GPRTERROR1 & GPRTERROR2 & GPRTERROR3 & GPTERROR1ARMS & GPRTERROR1N7 \\
\hline 0.1 & 1.7932 & 1.7538 & 1.3411 & 1.9455 & $2.3962^{*}$ & 0.9534 & 1.6888 & 1.7770 & 1.5407 \\
\hline 0.15 & $2.3524^{*}$ & $2.3278^{*}$ & 1.8053 & $2.0761^{*}$ & $2.8610^{*}$ & 1.3561 & $1.9804^{*}$ & $2.0592^{*}$ & $2.1229^{*}$ \\
\hline 0.2 & $3.0033^{*}$ & $2.6610^{*}$ & $2.4220^{*}$ & $2.8094^{*}$ & $2.7201^{*}$ & $2.1854^{*}$ & $2.8919^{*}$ & $2.6457^{*}$ & $2.0682^{*}$ \\
\hline 0.25 & $2.5161^{*}$ & $2.3292^{*}$ & $2.0450^{*}$ & $2.7806^{*}$ & $2.5924^{*}$ & 1.6131 & $2.4516^{*}$ & $2.8313^{*}$ & $2.0498^{*}$ \\
\hline 0.3 & $3.0077^{*}$ & $2.3370^{*}$ & $2.6049^{*}$ & $2.6874^{*}$ & $2.5766^{*}$ & $2.2567^{*}$ & $2.4927^{*}$ & $2.6867^{*}$ & $2.5045^{*}$ \\
\hline 0.35 & $3.7897^{*}$ & $2.9734^{*}$ & $2.9147^{*}$ & $3.1438^{*}$ & $3.2620^{*}$ & $2.6823^{*}$ & $2.7468^{*}$ & $3.0865^{*}$ & $2.5497^{*}$ \\
\hline 0.4 & $3.3830^{*}$ & $2.9315^{*}$ & $2.7440^{*}$ & $3.2148^{*}$ & $3.1061^{*}$ & $2.4414^{*}$ & $2.8366^{*}$ & $3.1942^{*}$ & $2.2429^{*}$ \\
\hline 0.45 & $2.8468^{*}$ & $2.7832^{*}$ & $2.5700^{*}$ & $3.4523^{*}$ & $2.9250^{*}$ & $2.5385^{*}$ & $3.0028^{*}$ & $3.2304^{*}$ & $2.4201^{*}$ \\
\hline 0.5 & $2.8308^{*}$ & $3.1121^{*}$ & $2.5512^{*}$ & $2.8696^{*}$ & $3.1083^{*}$ & 1.9512 & $2.7590^{*}$ & $3.0724^{*}$ & $2.4594^{*}$ \\
\hline 0.55 & $2.7742^{*}$ & $2.8067^{*}$ & $2.7421^{*}$ & $3.2556^{*}$ & $2.7615^{*}$ & $2.0970^{*}$ & $2.6048^{*}$ & $3.0816^{*}$ & $2.5765^{*}$ \\
\hline 0.6 & $2.6938^{*}$ & $2.9219^{*}$ & $2.8914^{*}$ & $3.7471^{*}$ & $3.0324^{*}$ & $2.1224^{*}$ & $2.9223^{*}$ & $3.2124^{*}$ & $2.5917^{*}$ \\
\hline 0.65 & $3.1471^{*}$ & $2.6746^{*}$ & $2.9359^{*}$ & $3.3756^{*}$ & $3.2137^{*}$ & $2.8436^{*}$ & $2.5842^{*}$ & $3.1858^{*}$ & $2.8918^{*}$ \\
\hline 0.7 & $2.5421^{*}$ & $2.1980^{*}$ & $2.7102^{*}$ & $2.9110^{*}$ & $2.8665^{*}$ & $2.4251^{*}$ & $2.4547^{*}$ & $3.1638^{*}$ & $2.4819^{*}$ \\
\hline 0.75 & $2.0397^{*}$ & $2.2044^{*}$ & $2.5286^{*}$ & $2.5424^{*}$ & $2.3159^{*}$ & 1.8970 & $2.2213^{*}$ & $2.9148^{*}$ & $2.1642^{*}$ \\
\hline
\end{tabular}




\begin{tabular}{|r|r|r|r|r|r|r|r|r|r|} 
& $2.0036^{*}$ & $1.9757^{*}$ & $2.2400^{*}$ & $2.5902^{*}$ & $2.2643^{*}$ & 1.8279 & $2.5038^{*}$ & $2.7370^{*}$ & $2.1022^{*}$ \\
\hline 0.85 & 1.5467 & 1.6433 & $1.9755^{*}$ & $2.0625^{*}$ & 1.8101 & 1.2789 & $1.9820^{*}$ & $2.5260^{*}$ & 1.5683 \\
\hline 0.9 & 1.6286 & 1.5886 & 1.9084 & 1.8153 & 1.7642 & 1.1895 & 1.6236 & $2.0262^{*}$ & 1.5136 \\
\hline
\end{tabular}

Note: See Notes to Table 2. 
Table 4. Causality-in-Quantiles Test for India

\begin{tabular}{|c|c|c|c|c|c|c|c|c|c|}
\hline & \multicolumn{9}{|c|}{ Panel A: Returns } \\
\hline Quantile & GPRME & GPR0 & GPRNOWAR & GPRTERROR0 & GPRTERROR1 & GPRTERROR2 & GPRTERROR3 & GPTERROR1ARMS & GPRTERROR1N7 \\
\hline 0.1 & 0.6740 & 0.5408 & 0.3693 & 0.6663 & 0.5835 & 0.5559 & 0.7177 & 0.9409 & 0.7111 \\
\hline 0.15 & 1.1669 & 0.7996 & 0.5621 & 1.1262 & 0.8069 & 0.8183 & 1.0916 & 0.9910 & 0.8523 \\
\hline 0.2 & 1.3153 & 0.5521 & 0.6131 & 1.5305 & 1.0944 & 0.7465 & 1.1146 & 1.2011 & 1.2108 \\
\hline 0.25 & 0.8911 & 0.6470 & 0.6459 & 1.1467 & 0.7961 & 0.6726 & 0.9976 & 1.0844 & 0.8752 \\
\hline 0.3 & 0.9024 & 0.7423 & 0.4876 & 1.1474 & 0.7682 & 0.5248 & 1.0146 & 0.8452 & 0.8662 \\
\hline 0.35 & 1.0026 & 1.0118 & 0.4901 & 1.2895 & 0.8941 & 0.6540 & 1.1032 & 1.2131 & 1.0035 \\
\hline 0.4 & 0.9343 & 0.8844 & 0.4577 & 1.1272 & 0.7707 & 0.7584 & 0.8771 & 1.4429 & 0.9181 \\
\hline 0.45 & 1.0747 & 1.0148 & 0.4689 & 1.2508 & 0.8962 & 0.9206 & 0.9926 & 1.5787 & 1.0974 \\
\hline 0.5 & 0.8906 & 0.7761 & 0.4220 & 1.2035 & 0.9380 & 0.9659 & 0.8847 & 1.3280 & 1.0967 \\
\hline 0.55 & 1.0224 & 0.7497 & 0.4754 & 1.4900 & 1.2740 & 1.1173 & 1.1599 & 1.7347 & 1.3003 \\
\hline 0.6 & 0.6877 & 0.9694 & 0.4363 & 1.0212 & 0.9007 & 0.9052 & 0.8165 & 1.4563 & 0.8895 \\
\hline 0.65 & 0.6097 & 1.1391 & 0.4920 & 0.6827 & 0.5837 & 0.7346 & 0.6280 & 1.0745 & 0.7308 \\
\hline 0.7 & 0.7062 & 0.8717 & 0.4639 & 0.8612 & 0.8099 & 0.7548 & 0.7282 & 0.9837 & 1.1033 \\
\hline 0.75 & 0.9547 & 1.1420 & 0.5306 & 1.0940 & 0.9563 & 0.8555 & 1.0223 & 1.2270 & 1.2833 \\
\hline 0.8 & 0.8502 & 1.1288 & 0.5364 & 0.8629 & 0.8041 & 0.6172 & 0.8157 & 0.8742 & 1.0472 \\
\hline 0.85 & 0.6962 & 1.2816 & 0.5796 & 0.6576 & 0.6131 & 0.6067 & 0.7161 & 0.9184 & 0.7060 \\
\hline \multirow[t]{2}{*}{0.9} & 0.4983 & 0.8831 & 0.3791 & 0.5550 & 0.5485 & 0.3659 & 0.5640 & 0.7655 & 0.6007 \\
\hline & \multicolumn{9}{|c|}{ Panel B: Volatility (Squared Returns) } \\
\hline Quantile & GPRME & GPR0 & GPRNOWAR & GPRTERROR0 & GPRTERROR1 & GPRTERROR2 & GPRTERROR3 & GPTERROR1ARMS & GPRTERROR1N7 \\
\hline 0.1 & 0.3318 & 0.1568 & 0.1845 & 0.3309 & 0.3505 & 0.1661 & 0.2623 & 0.3670 & 0.3275 \\
\hline 0.15 & 0.1540 & 0.1348 & 0.1335 & 0.1907 & 0.1479 & 0.1589 & 0.1555 & 0.2232 & 0.1285 \\
\hline 0.2 & 0.2162 & 0.2438 & 0.1331 & 0.2107 & 0.1856 & 0.1929 & 0.2005 & 0.2223 & 0.1831 \\
\hline 0.25 & 0.2496 & 0.2194 & 0.2270 & 0.2113 & 0.2451 & 0.2716 & 0.2328 & 0.2380 & 0.2543 \\
\hline 0.3 & 0.3054 & 0.2605 & 0.3318 & 0.2715 & 0.3774 & 0.2888 & 0.3346 & 0.4521 & 0.4013 \\
\hline
\end{tabular}




\begin{tabular}{|c|c|c|c|c|c|c|c|c|c|}
\hline 0.35 & 0.3615 & 0.2404 & 0.3739 & 0.3334 & 0.4000 & 0.2507 & 0.4585 & 0.4393 & 0.4305 \\
\hline 0.4 & 0.4714 & 0.1901 & 0.5476 & 0.2982 & 0.2747 & 0.1931 & 0.3128 & 0.4692 & 0.3725 \\
\hline 0.45 & 1.0112 & 0.3961 & 0.6099 & 0.5702 & 0.5881 & 0.3884 & 0.5874 & 0.7517 & 0.7320 \\
\hline 0.5 & 0.9790 & 0.4911 & 0.6557 & 0.5574 & 0.6567 & 0.4824 & 0.5605 & 0.7520 & 0.9168 \\
\hline 0.55 & 1.1833 & 0.4460 & 0.5774 & 0.7190 & 0.7266 & 0.4951 & 0.6117 & 0.5357 & 1.2581 \\
\hline 0.6 & 1.0842 & 0.5432 & 0.5901 & 0.7858 & 0.6668 & 0.4564 & 0.6665 & 0.5967 & 1.1296 \\
\hline 0.65 & 0.6694 & 0.5303 & 0.6068 & 0.4535 & 0.3937 & 0.3079 & 0.4373 & 0.4898 & 0.7111 \\
\hline 0.7 & 0.7839 & 0.4499 & 0.3895 & 0.4941 & 0.6023 & 0.3859 & 0.4178 & 0.5301 & 0.8600 \\
\hline 0.75 & 0.6552 & 0.3713 & 0.4703 & 0.5056 & 0.6472 & 0.4006 & 0.4548 & 0.5103 & 0.8530 \\
\hline 0.8 & 0.6643 & 0.4008 & 0.5019 & 0.4852 & 0.5742 & 0.4364 & 0.4138 & 0.6379 & 0.9088 \\
\hline 0.85 & 0.3413 & 0.2984 & 0.1623 & 0.1096 & 0.1740 & 0.1570 & 0.1045 & 0.2140 & 0.2803 \\
\hline 0.9 & 0.2346 & 0.2496 & 0.1361 & 0.1844 & 0.1995 & 0.1420 & 0.1815 & 0.2970 & 0.2536 \\
\hline & \multicolumn{9}{|c|}{ Panel C: Realized Volatility } \\
\hline Quantile & GPRME & GPR0 & GPRNOWAR & GPRTERROR0 & GPRTERROR1 & GPRTERROR2 & GPRTERROR3 & GPTERROR1ARMS & GPRTERROR1N7 \\
\hline 0.1 & 0.1403 & 0.1011 & 0.1070 & 0.1224 & 0.1299 & 0.1242 & 0.1245 & 0.1484 & 0.1271 \\
\hline 0.15 & 0.3077 & 0.2060 & 0.2372 & 0.2786 & 0.2541 & 0.2086 & 0.2698 & 0.2349 & 0.2749 \\
\hline 0.2 & 0.2289 & 0.2534 & 0.3656 & 0.1975 & 0.1827 & 0.1965 & 0.1772 & 0.2206 & 0.2224 \\
\hline 0.25 & 0.4469 & 0.3794 & 0.5439 & 0.3973 & 0.3810 & 0.4009 & 0.3859 & 0.4188 & 0.4399 \\
\hline 0.3 & 0.4373 & 0.3636 & 0.4664 & 0.4454 & 0.4013 & 0.4204 & 0.3809 & 0.4585 & 0.4697 \\
\hline 0.35 & 0.4514 & 0.3547 & 0.5579 & 0.4365 & 0.3977 & 0.4427 & 0.3518 & 0.4598 & 0.4904 \\
\hline 0.4 & 0.7030 & 0.5214 & 0.9173 & 0.7791 & 0.6551 & 0.5752 & 0.5919 & 0.5003 & 0.8191 \\
\hline 0.45 & 0.7468 & 0.5042 & 0.8857 & 0.8039 & 0.6369 & 0.5210 & 0.6652 & 0.4362 & 0.8232 \\
\hline 0.5 & 0.8058 & 0.4452 & 0.9888 & 0.8308 & 0.6596 & 0.5524 & 0.6595 & 0.3579 & 0.8647 \\
\hline 0.55 & 0.6795 & 0.3606 & 0.7675 & 0.7584 & 0.6043 & 0.4487 & 0.6095 & 0.3038 & 0.8588 \\
\hline 0.6 & 0.9242 & 0.4824 & 1.0765 & 1.0780 & 0.8998 & 0.6119 & 0.8002 & 0.4543 & 1.1336 \\
\hline 0.65 & 1.0661 & 0.3744 & 0.8799 & 1.1120 & 0.9662 & 0.7279 & 0.8595 & 0.4524 & 1.1847 \\
\hline 0.7 & 0.8228 & 0.2731 & 0.7082 & 0.8807 & 0.7700 & 0.6598 & 0.6395 & 0.3986 & 0.9699 \\
\hline 0.75 & 0.5845 & 0.3075 & 0.6979 & 0.7062 & 0.6273 & 0.5269 & 0.6025 & 0.3706 & 0.7460 \\
\hline
\end{tabular}




\begin{tabular}{|r|r|r|r|r|r|r|r|r|r|} 
& 0.3697 & 0.2726 & 0.3859 & 0.4073 & 0.3286 & 0.2705 & 0.3713 & 0.2221 & 0.3984 \\
\hline 0.85 & 0.2784 & 0.1341 & 0.1576 & 0.1733 & 0.1313 & 0.1309 & 0.1648 & 0.1487 & 0.1529 \\
\hline 0.9 & 0.2119 & 0.0825 & 0.0806 & 0.1160 & 0.1014 & 0.0968 & 0.1048 & 0.0785 & 0.1393 \\
\hline
\end{tabular}

Note: See Notes to Table 2. 
Table 5. Causality-in-Quantiles Test for China

\begin{tabular}{|c|c|c|c|c|c|c|c|c|c|}
\hline & \multicolumn{9}{|c|}{ Panel A: Returns } \\
\hline Quantile & GPRME & GPR0 & GPRNOWAR & GPRTERROR0 & GPRTERROR1 & GPRTERROR2 & GPRTERROR3 & GPTERROR1ARMS & GPRTERROR1N7 \\
\hline 0.1 & 1.7952 & 1.4708 & 1.4753 & 1.6062 & 1.5594 & 1.5418 & 1.4490 & 1.6326 & 1.6883 \\
\hline 0.15 & 1.7453 & 0.9555 & 0.9919 & 1.3635 & 1.3698 & 1.2970 & 1.1761 & 1.4017 & 1.5049 \\
\hline 0.2 & $2.4609^{*}$ & 1.1167 & 1.2708 & 1.8600 & 1.6327 & 1.3225 & 1.3624 & 1.3518 & 1.7468 \\
\hline 0.25 & $2.9828^{*}$ & 1.5798 & 1.7047 & $2.2543^{*}$ & 1.9432 & 1.4559 & 1.8493 & 1.3545 & $2.0409^{*}$ \\
\hline 0.3 & $2.3510^{*}$ & 1.2776 & 1.3309 & 1.6891 & 1.4500 & 1.2442 & 1.3733 & 1.0095 & 1.6501 \\
\hline 0.35 & $2.2800^{*}$ & 1.5855 & 1.5471 & 1.8776 & 1.5638 & 1.3218 & 1.4391 & 1.0751 & 1.5099 \\
\hline 0.4 & $1.9739^{*}$ & 1.3895 & 1.2701 & 1.8956 & 1.5738 & 1.0432 & 1.4846 & 1.2486 & 1.4473 \\
\hline 0.45 & 1.5883 & 1.0115 & 0.9796 & 1.4648 & 1.2685 & 0.7903 & 1.1001 & 1.0150 & 1.2637 \\
\hline 0.5 & 1.6357 & 1.3445 & 1.2084 & 1.4934 & 1.4941 & 1.2227 & 1.3353 & 1.3227 & 1.3514 \\
\hline 0.55 & 1.9807 & 1.2887 & 1.2166 & 1.7484 & 1.7969 & 1.2405 & 1.6085 & 1.5992 & 1.6427 \\
\hline 0.6 & 1.9160 & 1.1334 & 1.1515 & 1.6921 & 1.5772 & 1.1815 & 1.5851 & 1.6520 & 1.3950 \\
\hline 0.65 & 1.5994 & 1.2403 & 1.3421 & 1.5529 & 1.6414 & 1.1307 & 1.5279 & 1.6412 & 1.5287 \\
\hline 0.7 & 1.5320 & 1.2060 & 1.2853 & 1.4095 & 1.6589 & 1.1899 & 1.5442 & 1.7135 & 1.7890 \\
\hline 0.75 & 1.5580 & 1.3501 & 1.4300 & 1.5372 & 1.8118 & 1.0911 & 1.4955 & 1.9456 & 1.8115 \\
\hline 0.8 & 1.7203 & 1.5146 & 1.5426 & 1.7366 & 1.8963 & 1.3352 & 1.7186 & 1.9294 & 1.8734 \\
\hline 0.85 & 1.4347 & 1.1493 & 1.3534 & 1.3556 & 1.4579 & 1.3454 & 1.3376 & 1.4893 & 1.5863 \\
\hline \multirow[t]{2}{*}{0.9} & 0.8275 & 0.5061 & 0.6638 & 0.7866 & 0.8200 & 0.5979 & 0.6714 & 0.8825 & 0.8589 \\
\hline & \multicolumn{9}{|c|}{ Panel B: Volatility (Squared Returns) } \\
\hline Quantile & GPRME & GPR0 & GPRNOWAR & GPRTERROR0 & GPRTERROR1 & GPRTERROR2 & GPRTERROR3 & GPTERROR1ARMS & GPRTERROR1N7 \\
\hline 0.1 & 1.7926 & 1.4996 & 1.5084 & 1.5182 & 1.6589 & 1.3424 & 1.7679 & 1.7846 & 1.5143 \\
\hline 0.15 & $2.2739^{*}$ & $1.9777^{*}$ & 1.6146 & 1.8795 & 1.8637 & 1.5001 & $1.9770^{*}$ & $2.0449^{*}$ & $2.1041^{*}$ \\
\hline 0.2 & $2.2067^{*}$ & $2.0656^{*}$ & 1.9192 & $2.2054^{*}$ & $2.0608^{*}$ & 1.7219 & $2.1322^{*}$ & $2.2592^{*}$ & $2.1976^{*}$ \\
\hline 0.25 & $2.6387^{*}$ & $2.2930^{*}$ & 1.8396 & $2.4418^{*}$ & $2.3066^{*}$ & 1.8637 & $2.5205^{*}$ & $2.6829^{*}$ & $2.4825^{*}$ \\
\hline 0.3 & $3.1039^{*}$ & $2.4554^{*}$ & $2.2556^{*}$ & $2.9272^{*}$ & $2.6816^{*}$ & $2.1854^{*}$ & $2.8834^{*}$ & $2.7870^{*}$ & $2.8824^{*}$ \\
\hline
\end{tabular}




\begin{tabular}{|c|c|c|c|c|c|c|c|c|c|}
\hline 0.35 & $3.4957^{*}$ & $2.7509^{*}$ & $2.6017^{*}$ & $3.0840^{*}$ & $3.1876^{*}$ & $2.2938^{*}$ & $3.0502^{*}$ & $2.8960^{*}$ & $3.3791^{*}$ \\
\hline 0.4 & $3.9280^{*}$ & $3.1729^{*}$ & $2.8136^{*}$ & $3.4852^{*}$ & $4.1190^{*}$ & $2.2258^{*}$ & $3.8735^{*}$ & $3.1153^{*}$ & $4.1261^{*}$ \\
\hline 0.45 & $3.9107^{*}$ & $2.5728^{*}$ & $2.7861^{*}$ & $3.0797^{*}$ & $3.8372^{*}$ & $2.6605^{*}$ & $3.4912^{*}$ & $3.3386^{*}$ & $3.6175^{*}$ \\
\hline 0.5 & $3.7983^{*}$ & $2.6697^{*}$ & $2.1760^{*}$ & $3.0860^{*}$ & $3.4424^{*}$ & $2.4540^{*}$ & $3.5671^{*}$ & $3.3099^{*}$ & $3.6261^{*}$ \\
\hline 0.55 & $4.2928^{*}$ & $3.3165^{*}$ & $2.7508^{*}$ & $3.4782^{*}$ & $3.4467^{*}$ & $3.0415^{*}$ & $3.8281^{*}$ & $3.5795^{*}$ & $3.4468^{*}$ \\
\hline 0.6 & $4.6934^{*}$ & $3.2839^{*}$ & $2.8935^{*}$ & $3.5816^{*}$ & $3.8049^{*}$ & $3.3369^{*}$ & $3.4956^{*}$ & $4.0174^{*}$ & $3.5430^{*}$ \\
\hline 0.65 & $4.3759^{*}$ & $3.2781^{*}$ & $2.8962^{*}$ & $3.7803^{*}$ & $3.5659^{*}$ & $3.4440^{*}$ & $3.4973^{*}$ & $3.6828^{*}$ & $3.7949^{*}$ \\
\hline 0.7 & $3.7515^{*}$ & $3.4971^{*}$ & $2.5575^{*}$ & $3.3929^{*}$ & $3.0279^{*}$ & $3.3112^{*}$ & $2.9836^{*}$ & $3.5680^{*}$ & $3.6723^{*}$ \\
\hline 0.75 & $3.1863^{*}$ & $3.2534^{*}$ & $2.4046^{*}$ & $3.3945^{*}$ & $2.6783^{*}$ & $3.4257^{*}$ & $2.9383^{*}$ & $3.4253^{*}$ & $3.1507^{*}$ \\
\hline 0.8 & $2.9509^{*}$ & $2.5140^{*}$ & $2.4744^{*}$ & $3.1252^{*}$ & $2.5876^{*}$ & $3.2686^{*}$ & $2.7246^{*}$ & $2.8485^{*}$ & $2.8050^{*}$ \\
\hline 0.85 & $2.4580^{*}$ & $2.0471^{*}$ & 1.6938 & $2.5050^{*}$ & $2.1317^{*}$ & $2.4440^{*}$ & $2.0668^{*}$ & $2.5137^{*}$ & $2.5091^{*}$ \\
\hline \multirow[t]{2}{*}{0.9} & $2.1385^{*}$ & 1.8524 & 1.1265 & 1.8927 & 1.7597 & 1.6375 & 1.6238 & $1.9951^{*}$ & 1.8351 \\
\hline & \multicolumn{9}{|c|}{ Panel B: Realized Volatility } \\
\hline Quantile & GPRME & GPR0 & GPRNOWAR & GPRTERROR0 & GPRTERROR1 & GPRTERROR2 & GPRTERROR3 & GPTERROR1ARMS & GPRTERROR1N7 \\
\hline 0.1 & 1.2081 & 0.8305 & 0.9605 & 1.3462 & 1.1100 & 1.0240 & 1.2657 & 1.4067 & 1.0870 \\
\hline 0.15 & 1.6988 & 1.2293 & 1.3018 & $1.9666^{*}$ & 1.6027 & 1.2867 & 1.8464 & $2.0133^{*}$ & 1.5889 \\
\hline 0.2 & $2.1098^{*}$ & 1.4456 & 1.4794 & $2.2911^{*}$ & $2.0788^{*}$ & 1.6234 & $2.4057^{*}$ & $2.3902^{*}$ & $2.1266^{*}$ \\
\hline 0.25 & $2.3662^{*}$ & 1.7745 & $2.0032^{*}$ & $2.6220^{*}$ & $2.4634^{*}$ & $2.1239^{*}$ & $2.8022^{*}$ & $2.7804^{*}$ & $2.5682^{*}$ \\
\hline 0.3 & $2.8984^{*}$ & $2.1243^{*}$ & $2.5535^{*}$ & $3.0548^{*}$ & $2.9393^{*}$ & $2.6577^{*}$ & $2.9249^{*}$ & $3.2246^{*}$ & $3.1329^{*}$ \\
\hline 0.35 & $3.2558^{*}$ & $2.6518^{*}$ & $2.8948^{*}$ & $3.0736^{*}$ & $3.1131^{*}$ & $2.4648^{*}$ & $2.9148^{*}$ & $2.9820^{*}$ & $3.0639^{*}$ \\
\hline 0.4 & $3.3182^{*}$ & $2.6168^{*}$ & $3.0104^{*}$ & $3.1787^{*}$ & $3.3293^{*}$ & $2.2103^{*}$ & $2.6953^{*}$ & $2.7543^{*}$ & $3.2941^{*}$ \\
\hline 0.45 & $3.1667^{*}$ & $2.2380^{*}$ & $3.3215^{*}$ & $3.2395^{*}$ & $3.1228^{*}$ & $2.3761^{*}$ & $2.6232^{*}$ & $3.0321^{*}$ & $3.5075^{*}$ \\
\hline 0.5 & $3.7724^{*}$ & $2.6358^{*}$ & $3.7217^{*}$ & $3.8292^{*}$ & $3.5350^{*}$ & $2.9481^{*}$ & $3.0361^{*}$ & $2.7635^{*}$ & $4.0087^{*}$ \\
\hline 0.55 & $3.2642^{*}$ & $2.5187^{*}$ & $3.2322^{*}$ & $3.1073^{*}$ & $3.2691^{*}$ & $2.6217^{*}$ & $2.7158^{*}$ & $2.8883^{*}$ & $3.6129^{*}$ \\
\hline 0.6 & $3.2977^{*}$ & $2.1327^{*}$ & $3.0850^{*}$ & $3.0234^{*}$ & $3.0151^{*}$ & $2.5897^{*}$ & $2.3551^{*}$ & $2.8181^{*}$ & $3.1834^{*}$ \\
\hline 0.65 & $2.3442^{*}$ & 1.7195 & 1.8562 & $2.2546^{*}$ & $2.2215^{*}$ & 1.6512 & 1.9573 & $2.3454^{*}$ & $2.3554^{*}$ \\
\hline 0.7 & $2.1660^{*}$ & 1.5524 & 1.5674 & $2.1226^{*}$ & 1.8427 & 1.6312 & 1.8292 & 1.8103 & $2.4276^{*}$ \\
\hline 0.75 & $1.9739^{*}$ & 1.2218 & 1.7218 & 1.4934 & 1.4531 & 1.4506 & 1.4874 & $2.0205^{*}$ & $2.0452^{*}$ \\
\hline
\end{tabular}




\begin{tabular}{|r|r|r|r|r|r|r|r|r|r|} 
& 1.9047 & 1.0472 & 1.3186 & 1.5403 & 1.6471 & 1.4487 & 1.5964 & 1.7143 & 1.9001 \\
\hline 0.85 & 1.6099 & 1.0881 & 0.8654 & 1.2253 & 1.5128 & 0.8006 & 1.3045 & 1.6331 & 1.5540 \\
\hline 0.9 & 0.9846 & 0.8790 & 0.8721 & 1.0572 & 0.9515 & 0.5312 & 1.2874 & 1.1856 & 1.0417 \\
\hline
\end{tabular}

Note: See Notes to Table 2. 
Table 6. Causality-in-Quantiles Test for South Africa

\begin{tabular}{|c|c|c|c|c|c|c|c|c|c|}
\hline & \multicolumn{9}{|c|}{ Panel A: Returns } \\
\hline Quantile & GPRME & GPR0 & GPRNOWAR & GPRTERROR0 & GPRTERROR1 & GPRTERROR2 & GPRTERROR3 & GPTERROR1ARMS & GPRTERROR1N7 \\
\hline 0.1 & 0.0142 & 0.0142 & 0.0142 & 0.0142 & 0.0142 & 0.0142 & 0.0142 & 0.0142 & 0.0142 \\
\hline 0.15 & 0.0030 & 0.0030 & 0.0030 & 0.0030 & 0.0030 & 0.0030 & 0.0030 & 0.0030 & 0.0030 \\
\hline 0.2 & 0.0047 & 0.0047 & 0.0047 & 0.0047 & 0.0047 & 0.0047 & 0.0047 & 0.0047 & 0.0047 \\
\hline 0.25 & 0.0068 & 0.0068 & 0.0068 & 0.0068 & 0.0068 & 0.0068 & 0.0068 & 0.0068 & 0.0068 \\
\hline 0.3 & 0.0093 & 0.0093 & 0.0093 & 0.0093 & 0.0093 & 0.0093 & 0.0093 & 0.0093 & 0.0093 \\
\hline 0.35 & 0.0022 & 0.0022 & 0.0022 & 0.0022 & 0.0022 & 0.0022 & 0.0022 & 0.0022 & 0.0022 \\
\hline 0.4 & 0.0039 & 0.0039 & 0.0039 & 0.0039 & 0.0039 & 0.0039 & 0.0039 & 0.0039 & 0.0039 \\
\hline 0.45 & 0.0002 & 0.0002 & 0.0002 & 0.0002 & 0.0002 & 0.0002 & 0.0002 & 0.0002 & 0.0002 \\
\hline 0.5 & 0.0009 & 0.0009 & 0.0009 & 0.0009 & 0.0009 & 0.0009 & 0.0009 & 0.0009 & 0.0009 \\
\hline 0.55 & 0.0021 & 0.0021 & 0.0021 & 0.0021 & 0.0021 & 0.0021 & 0.0021 & 0.0021 & 0.0021 \\
\hline 0.6 & 0.0039 & 0.0039 & 0.0039 & 0.0039 & 0.0039 & 0.0039 & 0.0039 & 0.0039 & 0.0039 \\
\hline 0.65 & 0.0002 & 0.0002 & 0.0002 & 0.0002 & 0.0002 & 0.0002 & 0.0002 & 0.0002 & 0.0002 \\
\hline 0.7 & 0.0010 & 0.0010 & 0.0010 & 0.0010 & 0.0010 & 0.0010 & 0.0010 & 0.0010 & 0.0010 \\
\hline 0.75 & 0.0025 & 0.0025 & 0.0025 & 0.0025 & 0.0025 & 0.0025 & 0.0025 & 0.0025 & 0.0025 \\
\hline 0.8 & 0.0000 & 0.0000 & 0.0000 & 0.0000 & 0.0000 & 0.0000 & 0.0000 & 0.0000 & 0.0000 \\
\hline 0.85 & 0.0003 & 0.0003 & 0.0003 & 0.0003 & 0.0003 & 0.0003 & 0.0003 & 0.0003 & 0.0003 \\
\hline \multirow[t]{2}{*}{0.9} & 0.0142 & 0.0142 & 0.0142 & 0.0142 & 0.0142 & 0.0142 & 0.0142 & 0.0142 & 0.0142 \\
\hline & \multicolumn{9}{|c|}{ Panel B: Volatility (Squared Returns) } \\
\hline Quantile & GPRME & GPR0 & GPRNOWAR & GPRTERROR0 & GPRTERROR1 & GPRTERROR2 & GPRTERROR3 & GPTERROR1ARMS & GPRTERROR1N7 \\
\hline 0.1 & 0.2308 & 0.1663 & 0.1141 & 0.2027 & 0.2143 & 0.0904 & 0.2451 & 0.2509 & 0.1477 \\
\hline 0.15 & 0.2574 & 0.2010 & 0.1241 & 0.2180 & 0.2343 & 0.0915 & 0.1889 & 0.2064 & 0.1713 \\
\hline 0.2 & 0.2705 & 0.1867 & 0.0724 & 0.3024 & 0.3595 & 0.1457 & 0.2282 & 0.4243 & 0.2896 \\
\hline 0.25 & 0.5795 & 0.1705 & 0.1442 & 0.4833 & 0.6442 & 0.2991 & 0.3202 & 0.3795 & 0.5707 \\
\hline 0.3 & 0.4230 & 0.1778 & 0.1412 & 0.3702 & 0.4321 & 0.2653 & 0.2740 & 0.2271 & 0.4004 \\
\hline
\end{tabular}




\begin{tabular}{|c|c|c|c|c|c|c|c|c|c|}
\hline 0.35 & 0.4910 & 0.2315 & 0.1623 & 0.4586 & 0.5029 & 0.2995 & 0.3839 & 0.3339 & 0.4266 \\
\hline 0.4 & 0.3019 & 0.2153 & 0.1344 & 0.4033 & 0.3550 & 0.2395 & 0.3728 & 0.2353 & 0.3358 \\
\hline 0.45 & 0.1790 & 0.1634 & 0.0820 & 0.1831 & 0.1879 & 0.1940 & 0.2316 & 0.3897 & 0.1359 \\
\hline 0.5 & 0.2202 & 0.0897 & 0.0535 & 0.2038 & 0.2610 & 0.2644 & 0.2729 & 0.4351 & 0.2240 \\
\hline 0.55 & 0.3487 & 0.0950 & 0.0804 & 0.2887 & 0.4176 & 0.4017 & 0.3510 & 0.7225 & 0.4335 \\
\hline 0.6 & 0.1973 & 0.0926 & 0.1140 & 0.2060 & 0.2903 & 0.4174 & 0.1785 & 0.4334 & 0.3094 \\
\hline 0.65 & 0.1161 & 0.0897 & 0.0813 & 0.1096 & 0.1197 & 0.1860 & 0.1272 & 0.3403 & 0.1451 \\
\hline 0.7 & 0.1915 & 0.1038 & 0.1179 & 0.1882 & 0.1873 & 0.2674 & 0.1330 & 0.4177 & 0.1661 \\
\hline 0.75 & 0.1447 & 0.1113 & 0.0857 & 0.1543 & 0.1884 & 0.2911 & 0.1185 & 0.3217 & 0.1647 \\
\hline 0.8 & 0.1757 & 0.1229 & 0.1847 & 0.2049 & 0.2335 & 0.2878 & 0.1121 & 0.2961 & 0.2056 \\
\hline 0.85 & 0.1327 & 0.0795 & 0.0728 & 0.1815 & 0.1419 & 0.1233 & 0.1579 & 0.3398 & 0.1132 \\
\hline 0.9 & 0.0885 & 0.0449 & 0.0433 & 0.0795 & 0.1088 & 0.1243 & 0.0643 & 0.5064 & 0.0616 \\
\hline & \multicolumn{9}{|c|}{ Panel C: Realized Volatility } \\
\hline Quantile & GPRME & GPR0 & GPRNOWAR & GPRTERROR0 & GPRTERROR1 & GPRTERROR2 & GPRTERROR3 & GPTERROR1ARMS & GPRTERROR1N7 \\
\hline 0.1 & $2.9973^{*}$ & 1.3759 & 1.3232 & $2.0674^{*}$ & 1.8756 & 1.7496 & 1.5522 & 1.8541 & 1.5284 \\
\hline 0.15 & $3.4695^{*}$ & 1.8161 & 1.6845 & $2.8642^{*}$ & $2.6141^{*}$ & $2.1215^{*}$ & $2.1528^{*}$ & $2.6776^{*}$ & $2.1594^{*}$ \\
\hline 0.2 & $3.3923^{*}$ & 1.7328 & 1.8227 & $2.5056^{*}$ & $2.3033^{*}$ & $2.2969^{*}$ & $1.9852^{*}$ & $2.6343^{*}$ & $2.1032^{*}$ \\
\hline 0.25 & $4.2847^{*}$ & $2.0802^{*}$ & $2.2339^{*}$ & $3.5765^{*}$ & $2.9848^{*}$ & $3.0910^{*}$ & $2.4321^{*}$ & $2.5544^{*}$ & $2.6840^{*}$ \\
\hline 0.3 & $4.9217^{*}$ & 1.8622 & $2.2686^{*}$ & $3.8841^{*}$ & $3.4752^{*}$ & $3.6656^{*}$ & $2.5104^{*}$ & $2.3323^{*}$ & $3.3860^{*}$ \\
\hline 0.35 & $4.3669^{*}$ & 1.3956 & 1.4750 & $3.5163^{*}$ & $2.9262^{*}$ & $3.0940^{*}$ & $1.9643^{*}$ & 1.4200 & $3.2686^{*}$ \\
\hline 0.4 & $4.8676^{*}$ & 1.8320 & 1.5305 & $4.0145^{*}$ & $3.2974^{*}$ & $3.5827^{*}$ & $2.2131^{*}$ & 1.8061 & $3.3515^{*}$ \\
\hline 0.45 & $4.5112^{*}$ & 1.4465 & 1.7213 & $3.8334^{*}$ & $3.4964^{*}$ & $3.0125^{*}$ & $2.3004^{*}$ & 1.8752 & $3.3964 *$ \\
\hline 0.5 & $2.8023^{*}$ & 1.0968 & 1.1322 & $2.4742^{*}$ & 1.8180 & 1.8130 & 1.3767 & 1.2690 & $1.9943^{*}$ \\
\hline 0.55 & $2.8502^{*}$ & 0.9745 & 1.0452 & $2.5952^{*}$ & 1.9101 & 1.5538 & 1.8787 & 1.2158 & 1.8749 \\
\hline 0.6 & $3.1065^{*}$ & 1.0337 & 0.9950 & $2.4864^{*}$ & $2.2411^{*}$ & 1.4595 & 1.7624 & 1.1084 & 1.9010 \\
\hline 0.65 & $2.3027^{*}$ & 0.9609 & 0.7753 & 1.6952 & 1.5380 & 1.3355 & 1.1290 & 1.1787 & 1.2980 \\
\hline 0.7 & $2.1419^{*}$ & 1.2842 & 0.7358 & 1.9397 & 1.4827 & 1.4148 & 1.4210 & 1.1759 & 1.3706 \\
\hline 0.75 & 1.7229 & 1.0809 & 0.8354 & 1.5310 & 1.3611 & 1.1732 & 1.2645 & 1.1036 & 1.3289 \\
\hline
\end{tabular}




\begin{tabular}{|r|r|r|r|r|r|r|r|r|r|} 
\\
\hline 0.8 & 1.8871 & 0.9641 & 0.6000 & 1.9057 & 1.7580 & 1.1940 & 1.6857 & 1.0182 & 1.3994 \\
\hline 0.9 & 0.5785 & 1.0134 & 0.2828 & 0.9005 & 0.6822 & 0.4044 & 0.6996 & 0.7682 & 0.5334 \\
\hline Note: See Notes to & 0.2577 & 0.8110 & 0.1928 & 0.3236 & 0.1812 & 0.2230 & 0.2900 & 0.5227 & 0.2693 \\
\hline
\end{tabular}


found to have a more consistent effect on market volatility measures, rather than returns, implying the presence of possible volatility spillovers into these markets as a result of their exposures with respect to geopolitical tensions. It is also possible that geopolitical risk indexes capture the global uncertainties that contribute to volatility spillovers across these stock markets. To that end, although beyond the scope of this particular study, it would be interesting to examine whether GPRs have a significant effect in the transmission of return and volatility shocks across these markets.

Examining the findings across alternative quantiles of the conditional distribution of returns, we observe that the effect of GPRs on market volatility is relatively stronger and more consistent at quantiles below the median, suggesting that GPRs in fact contribute to bad volatility in these markets. The stronger and more consistent effect of GPRs during periods of market downturns (or distress) is consistent with the recent finding by Mensi et al. (2016) who report asymmetric relationships between political and financial risk ratings and the BRICS stock market returns. To that end, it can be argued that the risk exposure of these markets with respect to GPRs is a contributing factor to country-level political and financial risk ratings, thus indirectly driving the asymmetric relationships observed between these ratings and stock market returns.

From a policy making perspective, this is indeed bad news for market regulators in these emerging nations as geopolitical shocks, in particular terror related incidents are largely unanticipated, and these countries are often subject to the flow of hot money in and out of their financial markets which can be triggered by geopolitical tensions, among other reasons. Therefore, given the finding that GPRs drive bad volatility in these markets, one can argue that geopolitical shocks can potentially transition these markets into a 'crash regime' triggered by a deadly combination of sudden capital outflows and the presence of herd behavior in the domestic market which is often the case for most emerging markets (e.g. Yao et a., 2014; 
Akinsomi et al., 2016). To that end, a future research question is whether GPR shocks contribute to herd behavior in these markets and whether this is a factor behind the 'volatility effect' that is documented in this paper.

Examining the findings across the BRICS nations, we see in Table 3 that Russia bears the greatest risk exposure to GPRs with significant causality observed from GPRs to both market return and volatility in this market. The risk exposure of Russia with respect to GPRs is consistent across all alternative GPR indexes, suggesting that investors in this market respond to news regarding geopolitical tensions regardless of the nature of the shock, whether it is related to a terrorist incident, arms control or war. A similar pattern is also observed in Table 5 for China, however, only in the case of market volatility measures, suggesting that GPRs, regardless of the nature of the incident, have a robust effect on stock market volatility in this country. The widespread effect of GPR indexes for Russia and China are in fact consistent with Hammoudeh et al. (2013) who note that these two markets hold strong sensitivity to political risk and our findings suggest that GPRs may be the driving force behind country-level political risk exposures in these nations.

On the other end of the spectrum, the findings reported in Table 4 suggest that India is the most resilient BRICS nation to GPR shocks, with no significant causal relationships observed neither in the case of market returns nor the alternative volatility measures reported in Panels A, B and C, respectively. Roubini (2009) notes the presence of strong domestic demand in India relative to other BRICS nations and that India carries a low dollar share in its foreign exchange reserves compared to Russia, China and Brazil. Therefore, despite the fact that India is major commodity importer, it can be argued that its relatively lower exposure to the U.S. dollar along with other factors including strong domestic demand and a large consumption base, help cushion the effect of GPRs on this market. It is also possible that capital flows into this market 
due to the IT boom experienced during a significant portion of the sample period has further helped cushion the negative effects of geopolitical tensions (Henkel, 2012).

Examining the findings for Brazil and S. Africa in Tables 2 and 6, respectively, we see that GPRs have some effect on market volatility in these countries, while no causality is found in the case of returns. However, unlike the case for Russia and China, these effects on volatility are not as strong and consistent across the different GPR indexes. Despite the fact that these two countries are major commodity exporters, the relatively weaker results observed in Tables 2 and 6 suggest that volatility transmissions across the BRICS nations may be at play, transmitting GPR driven volatility shocks, particularly from Russia and China, into these stock markets. Roubini (2009) notes that Chinese growth may be of more significance to Brazil than that of the overall global economy. To that end, it can be argued that volatility shocks, partially driven by geopolitical tensions, are transmitted into this market via channels of export trades and foreign direct investments from China in particular.

Overall, our findings suggest that GPRs have heterogeneous effects across the BRICS stock markets, suggesting that these markets do not respond to geopolitical tensions in a uniform way. While country-specific factors may help explain these heterogeneous reactions, the findings suggest that some markets, including Brazil and S. Africa, suffer from volatility transmissions from other BRICS nations like China and Russia that seem to be the most vulnerable to GPR shocks. Nevertheless, whatever the underlying channel of risk transmission may be, it is important that these emerging nations put in place the kind of reforms that can help strengthen domestic demand, reduce exposure to a single currency in their foreign reserves and create the 
tools and mechanisms that will allow local investor diversify country-specific risks in their portfolios. ${ }^{6}$

\section{Conclusion}

This paper examines the effect of geopolitical uncertainty on return and volatility dynamics in the BRICS stock markets via nonparametric causality-in-quantiles tests. We find that the effect of geopolitical risks is heterogeneous across the BRICS stock markets, suggesting that news regarding geopolitical tensions do not affect return dynamics in these markets in a uniform way. In general, GPRs are found to have a more consistent effect on market volatility measures, rather than returns, implying the presence of possible volatility spillovers into these markets as a result of their exposures with respect to geopolitical tensions. The effect of GPRs on market volatility is found to be more consistent at quantiles below the conditional median of returns, suggesting that GPRs in fact contribute to bad volatility in these markets.

Comparing the findings across the BRICS markets, we find that Russia and China lead the pack with relatively more significant risk exposures to GPRs, consistent across the different GPR indexes examined. This finding suggests that these markets respond to news regarding geopolitical tensions regardless of the nature of the shock, whether it is related to a terrorist

\footnotetext{
${ }^{6}$ Based on the suggestion of an anonymous referee, to accommodate for the possibility of an important omitted variable like the US stock price, we undertook an indirect approach of testing the robustness of our causality-inquantiles test. Unlike linear test of causality, which can be multivariate, all known nonlinear tests of causality are in fact bivariate (see for example, Heimstra and Jones (1994), Diks and Panchenko (2005, 2006), Nishiyama et al., (2011), Jeong et al., (2011)). Our indirect approach involves two steps: First, we estimate a linear causality model with US stock returns (or realized volatility) only in the regression involving BRICS stock returns (realized volatility); and second, recover the residuals from these models and apply our nonparametric causality-in-quantiles test on these residuals and squares of it. So, the idea here is to create a filtered series for the stock returns and realized volatility, whose movements are now no longer due to the US stock returns or realized volatility. Note that, for our purpose, we use the S\&P 500 stock price data sourced from the Datastream database. In general, our results we consistent whether we use the actual returns series or the filtered series (errors). However, there was one exception, with us now detecting causality in squared returns for India with the filtered series, which was not the case before with the actual returns series. Since our results are virtually unchanged with the indirect inclusion of the S\&P500, these have not been formally reported in the paper to save space, but are available upon request from the authors. In addition note also, we decided to report these results in a footnote rather than formally in the text, since the linear models involving the BRICS and US stock returns and realized volatility used to recover the filtered series, also suffer from misspecification due to nonlinearity as shown by the BDS test. Hence, the results based on the filtered residuals, cannot be completely relied upon. Results of the BDS test are again available upon request from the authors.
} 
incident, arms control or war. On the other hand, India is found to be the most resilient BRICS nation to GPR shocks, with no significant causal relationships observed, while some effect, particularly on market volatility measures, is observed in the case of Brazil and S. Africa. Overall, the findings suggest that GPRs may be transmitted via volatility interactions across the BRICS markets with Russia and China acting as the major transmitters of volatility shocks partially driven by geopolitical uncertainties.

We argue that a combination of factors including exposure to political and financial risks, the strength of domestic demand and exposure to the U.S dollar in foreign exchange reserves drive the heterogeneity in the reaction of these emerging stock markets to geopolitical risks. Noting that geopolitical shocks and in particular terrorist incidents are largely unanticipated, our findings underscore the importance of a strong financial sector that can help return the market to stability and an open economy that allows local investors to diversify country specific risks in their portfolios. This issue is particularly important for emerging markets, like those in the BRICS, as these markets are often subject to the flow of 'hot money' in and out of the financial system that can be rather destabilizing given their exposure to geopolitical risks, as shown in this study, as well as the presence of herd behavior which is often the case for most emerging markets. To that end, several research questions remain: (i) Do GPR shocks contribute to herd behavior in these markets and whether this is a factor behind the 'volatility effect' that is documented in this paper? and (ii) Do GPR shocks play a role in the volatility transmission process across these markets and which BRICS markets act as main transmitters of risks due to GPRs? We leave these questions to future research. 


\section{References}

Abadie, A., Gardeazabal, J. 2008. Terrorism and the world economy. European Economic Review, 52 (1), 1-27.

Akinsomi, K., Balcilar, M., Demirer, R., Gupta, R., 2016. The Effect of Gold Market Speculation on REIT Returns in South Africa: A Behavioral Perspective. Department of Economics, University of Pretoria, Working Paper No. 201643.

Andersen T.G., and Bollerslev T. 1998. Answering the Skeptics: Yes, Standard Volatility Models Do Provide Accurate Forecasts. International Economic Review, 39 (4), 885-905.

Antonakakis, N., Chatziantoniou, I., and Filis, G. 2014. Spillovers between oil and stock markets at times of geopolitical unrest and economic turbulence. MPRA Working Paper No. 59760.

Arin, K.P., Ciferri, D., and Spagnolo, N., 2008. The price of terror: The effects of terrorism on stock market returns and volatility. Economics Letters 101, 164-167.

Balcilar, M., Gupta, R., Kyei, C., and Wohar, M.E. 2016. Does Economic Policy Uncertainty Predict Exchange Rate Returns and Volatility? Evidence from a Nonparametric Causality-inQuantiles Test. Open Economies Review, 27 (2), 229-250.

Balcilar, M., Gupta, R., Pierdzioch, C., and Wohar, M.E. 2016. Do Terror Attacks Affect the Dollar-Pound Exchange Rate? A Nonparametric Causality-in-Quantiles Analysis. Department of Economics, University of Pretoria, Working Paper No. 201608.

Balcilar, M., Gupta, R., Pierdzioch, C., and Wohar, M.E., (Forthcoming a). Terror Attacks and Stock-Market Fluctuations: Evidence Based on a Nonparametric Causality-in-Quantiles Test for the G7 Countries. European Journal of Finance.

Balcilar, M., Bekiros, S., and Gupta, R. (Forthcoming b). The role of news-based uncertainty indices in predicting oil markets: a hybrid nonparametric quantile causality method. Empirical Economics.

Barros, C.P., Gil-Alana, L. 2008. Stock market returns and terrorist violence: evidence from the Basque Country. Applied Economics Letters, 16 (15), 1575-1579.

Bekiros, S., Gupta, R., and Majumdar, A., (Forthcoming). Incorporating Economic Policy Uncertainty in US Equity Premium Models: A Nonlinear Predictability Analysis. Finance Research Letters.

Cakan, E., and Gupta, R. 2016. Does U.S. Macroeconomic News Make the South African Stock Market Riskier? Department of Economics, University of Pretoria, Working Paper No. 201646. 
Caldara, D., and Iacoviello, M. 2016. Measuring Geopolitical Risk. Working Paper, Board of Governors of the Federal Reserve Board.

Chen, A.H., and Siems, T.F., 2004. The effects of terrorism on global capital markets. European Journal of Political Economy 20, 349-366.

Chesney, M., Reshetar, G., Karaman, M. 2011. The impact of terrorism on financial markets: an empirical study. Journal of Banking and Finance, 35 (2), 253-267.

Christofis, N., Kollias, C., Papadamou, S., and Stagiannis, A. 2013. Istanbul Stock Market's Reaction to Terrorist Attacks. Doğuş Üniversitesi Dergisi, 14 (2), 153-164.

Chuliá, H., Climent, F.J., Soriano, P., and Torró, H., 2009. Volatility transmission patterns and terrorist attacks. Quantitative Finance 9 (5), 607-619.

Diks, C.G.H., and Panchenko, V. (2005). A note on the Hiemstra-Jones test for Granger noncausality. Studies in Nonlinear Dynamics and Econometrics, 9, 1-7.

Diks, C. G. H., and Panchenko, V. 2006. A new statistic and practical guidelines for nonparametric Granger causality testing. Journal of Economic Dynamics and Control, 30(9-10), $1647-1669$.

Drakos, K. 2004. Terrorism-induced structural shifts in financial risk: airline stocks in the aftermath of the September 11th terror attacks. European Journal of Political Economy 20 (2), 435-446.

Drakos, K. 2010. Terrorism activity, investor sentiment and stock returns. Review of Financial Economics, 19 (3), 128-135.

Eldor, R.,and Melnick, R., 2004. Financial markets and terrorism. European Journal of Political Economy 20, 367-386.

Fernandez, V. 2008. The war on terror and its impact on the long term volatility of financial markets. International Review of Financial Analysis, 17 (1), 1-26.

Gupta, R., Majumdar, A., Pierdzioch, C., and Wohar, M.E. 2016. Do Terror Attacks Predict Gold Returns? Evidence from a Quantile-Predictive-Regression Approach. Department of Economics, University of Pretoria, Working Paper No. 201626.

Hammoudeh, S., R. Sari, M. Uzunkaya, and T. Liu, 2013. The Dynamics of BRICS's Country Risk Ratings and Domestic Stock Markets, U.S. Stock Market and Oil Price, Mathematics and Computers in Simulation 94, 277-94.

Henkel, A. 2012. BRICS financial markets as diverse as the countries. Russia and India Report: https://in.rbth.com/articles/2012/07/13/brics financial markets as diverse as the countri es 16325. 
Hiemstra, C. and Jones, J. D. (1994). Testing for linear and nonlinear Granger causality in the stock price-volume relation. Journal of Finance, 49(5), 1639-1664.

Hon, M.T., Strauss, J., and Yong, S.-Y., 2004. Contagion in financial markets after September 11: myth or reality? Journal of Financial Research 27: 95-114.

Jeong, K., Härdle, W. K. and Song, S., 2012. A consistent nonparametric test for causality in quantile. Econometric Theory 28, 861-887.

Johnston, B., and O. Nedelescu, 2006. The impact of terrorism on financial markets. Journal of Financial Crime 13: 7-25.

Karolyi, A., and Martell, R., 2010. Terrorism and the stock market. International Review of Applied Financial Issues and Economics 2: 285-314.

Kollias, C., Papadamou, S., and Stagiannis, A. 2010. Armed conflicts and capital markets: the case of the Israeli military offensive in the Gaza Strip. Defence and Peace Economics, 21 (4), 357-365.

Kollias, C., Papadamou, S., and Stagiannis, A. 2011a. Terrorism and capital markets: the effects of the Madrid and London bomb attacks. International Review of Economics and Finance, 20 (4), 532-541.

Kollias, C., Papadamou, S., and Stagiannis, A. 2011b. Stock markets and terrorist attacks: comparative evidence from a large and a small capitalization market. European Journal of Political Economy, 27 (S1), S64-77.

Kollias, C., Papadamou, S., and Arvanitis, V. 2013a. Does terrorism affect the stockbond covariance? Evidence from European countries. Southern Economic Journal, 79 (4), 832-548.

Kollias, C., Kyrtsou, C., and Papadamou, S. 2013b. The Effects of Terrorism and War on the Oil and Prices - Stock Indices Relationship. Energy Economics, 40, 743-752.

Mensi, W., Hammoudeh, S., Reboredo, J.C., \& Nguyen, D. K. 2014. Do global factors impact BRICS stock markets? A quantile regression approach. Emerging Markets Review, 19(C), 1-17.

Mensi, W., Hammoudeh, S., Yoon, S-M., \& Nguyen, D. K. 2016. Asymmetric Linkages between BRICS Stock Returns and Country Risk Ratings: Evidence from Dynamic Panel Threshold Models. Review of International Economics, 24(1), 1-19.

Nikkinen, J., Omran, M., Sahlstrom, P., Aijo, J. 2008. Stock returns and volatility following the September 11 attacks: evidence from 53 equity markets. International Review of Financial Analysis, 17 (1), 27-46.

Nishiyama, Y., Hitomi, K., Kawasaki, Y., and Jeong, K. 2011. A consistent nonparametric Test for nonlinear causality - specification in time series regression. Journal of Econometrics 165, $112-127$. 
Rapach, D., and G. Zhou. 2013. Forecasting Stock Returns: in Handbook of Economic Forecasting, Volume 2A, Graham Elliott and Allan Timmermann (Eds.) Amsterdam: Elsevier, $328-383$.

Roubini, N. 2009. The BRICS: An Analysis. Forbes Magazine (June 18, 2009). http://www.forbes.com/2009/06/17/bric-brazil-russia-india-china-renminbi-yekaterinbergopinions-columnists-roubini.html.

Yao, J., Ma, C., He, W.P., 2014. Investor herding behaviour of Chinese stock market. Int. Rev. Econ. Financ. 29, 12-29. 